\title{
En los inicios del Renacimiento. La cúpula brunelleschiana y reflexiones sobre Paolo Uccello
}

\author{
Diego SuÁrez Quevedo \\ Universidad Complutense de Madrid \\ disuarez@ucm.es
}

Recibido: 11-01-2015

Aceptado: 03-09-2015

\section{RESUMEN}

Tomando como eje el año 1436 en que es inaugurada solemnemente, a falta de su linterna, la cúpula de la catedral de Florencia y, siendo además este año el de la realización del Acuto de Paolo Uccello, se trata de glosar y reflexionar, unos quinientos ochenta años después, tanto sobre la paradigmática construcción de Brunelleschi, como sobre Uccello y su importante contribución a la historia del arte.

Palabras clave: Brunelleschi. Florencia. 1436. Cúpula de Santa Maria del Fiore. Guillaume Dufay. Nuper rosarum flores. Papa Eugenio IV. Uccello. Perspectiva Naturalis. Ghiberti. Acuto. Batallas. Frescos del Chiostro Verde de Santa Maria Novella. Predella di Urbino. Caccia de Oxford.

\section{In the Early Renaissance. Brunelleschi's Dome and Reflexions about Paolo Uccello}

\begin{abstract}
Taking as main idea the year 1436 when is solemnly inaugurated, in the absence of its small tower [or cupola], the dome of Florence cathedral and, being this the year of Paolo Uccello's Acuto, it's about to gloss and reflect, five hundred and eighty years later, on the paradigmatic Brunelleschi's construction and on Uccello and its important contribution to the history of art.
\end{abstract}

Key Words: Brunelleschi. Florence. 1436. Dome of Santa Maria del Fiore. Guillaume Dufay. Nuper rosarum flores. Pope Eugene IV. Uccello. Perspectiva Naturalis. Ghiberti. Acuto. Batles. Chiostro Verde'frescoes of Santa Maria Novella. Predella di Urbino. Caccia of Oxford.

Sumario: Brunelleschi y la cúpula de la catedral de Florencia. Addenda [Extractos del Nuper rosarum flores de Guillaume Dufay, 1436]. Uccello, consideraciones y parámetros globales. De los inicios al Acuto y las Batallas. Búsquedas y hallazgos, 1436-1460. Uccello, últimas aportaciones. (Addenda: Alhazén, Bacon, Vitellone). 


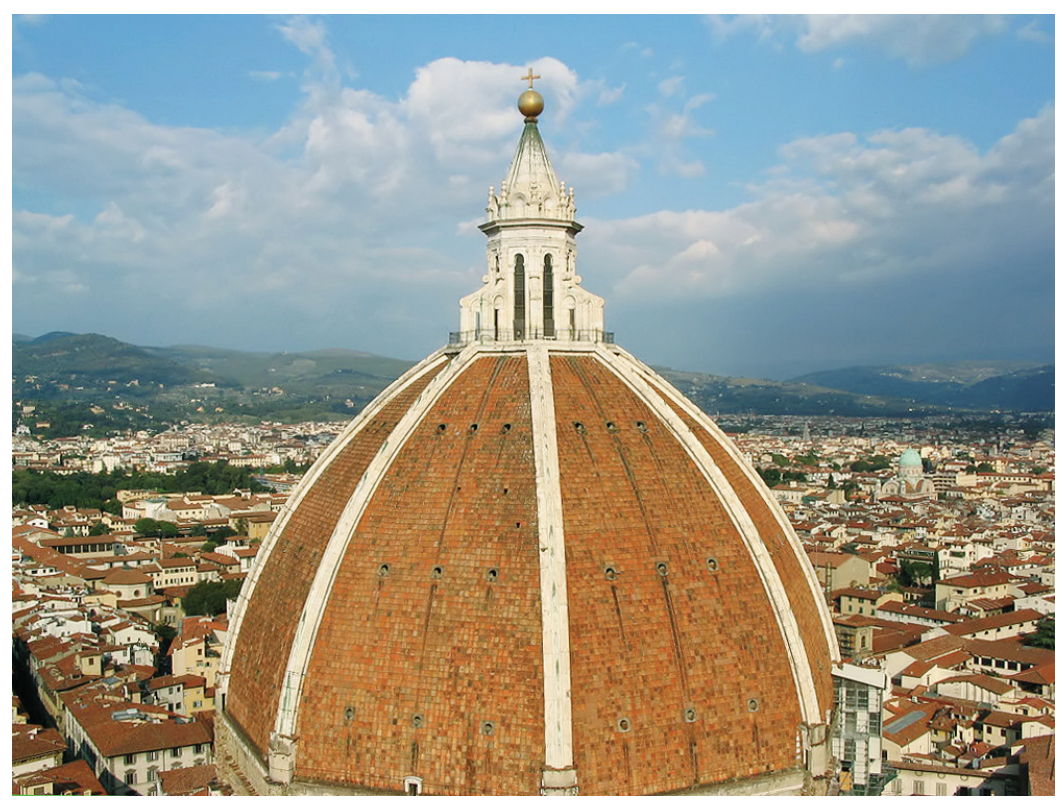

Fig. 1. Cúpula brunelleschiana, Florencia.

Se trata de encarar dos temas -Cupola de la catedral de Florencia y Paolo Uccello ${ }^{1}-$ bien diversos, en función del año 1436, en que Brunelleschi culminaba - a falta de la linterna, que su autor no verá concluida- esta paradigmática obra; es asimismo la data de la primera obra documentada de Uccelllo, el Acuto, sito precisamente en el interior del citado templo de la ciudad del Arno. Van a ser, por tanto, miradas, reflexiones y valoraciones pautadas y perfiladas unos quinientos ochenta años después -que se cumplirán en 2016- y que, como significativos y sugestivos hitos en los inicios del Renacimiento, se proponen como cuestiones independientes -el término mini-capítulos, resulta hasta pretencioso- que, en cambio, tienen como vértice común el espíritu investigador y afán de experimentación de ambos artistas.

En cualquier caso, son consideraciones sin intención conclusiva alguna, siempre abiertas y "a debate", y sí, hasta donde sea capaz, como detonantes de toda una suerte de aspectos interdisciplinares, apelando a una "saludable" transversalidad que eluda etiquetas y compartimentaciones estrictas. Pretendo plantear un discurso cuya coherencia quede sustentada en el contexto histórico-artístico, político-social y religioso, imperante en el Tre-Quattrocento.

1 En ambos casos, se trata de una suerte de recuerdo-homenaje; respecto a la cúpula brunelleschiana, válido y evidente per se. En el caso de Uccello, también en función de los quinientos cuarenta años, que se cumplen este 2015, de su fallecimiento en 1475, con la profunda convicción de la importancia de su personalísima aportación artística, en el contexto del denominado "Primer Renacimiento" en Florencia. 


\section{Brunelleschi y la cúpula de la catedral de Florencia}

El 25 de abril de 1436 -fin de año, 1435, en el entonces vigente calendario florentino- el papa Eugenio IV, estante la corte pontificia en la ciudad del Arno desde 1434, consagraba en solemne ceremonia la recién concluida cúpula de Santa Maria del Fiore, a la que restaba su linterna, cuyo proceso constructivo se iniciaba ese mismo año. La solemnidad del acto quedó asegurada mediante la interpretación del motete isorrítmico Nuper Rosarum Flores, compuesto por Guillaume Dufay para la ocasión con precisas referencias al templo, su advocación, a Florencia y al propio pontífice ${ }^{2}$. Se cumplirán, por tanto, en 2016, quinientos ochenta años de su conclusión y de estos eventos inaugurales; obra paradigmática de la cultura artística occidental sin paliativo alguno, no precisa de exhaustivas presentaciones. Su arquitecto, Filippo di Ser Brunellesco Lapi, Filippo Brunelleschi, detto Pippo (Florencia: 1377-1446), remataba así un largo y complicado proceso iniciado en 1417. (Fig. 1)

El impacto de la obra, hito del Duomo, su significación urbana en todos los sentidos -supraurbana, cabría decir-y, en su contexto, referente primigenio de "civilidad", pleno de ribetes nacionalistas y utilizando el vulgar como vindicación de la lengua de Dante, acaso no exista un testimonio más contundente que el elogio que Alberti dedica a Brunelleschi y a su CúPULA (así con mayúsculas) en la dedicatoria de su Della pittura (redactado c. 1435-1436, precisamente), reclamando su admiración hacia "una estructura tan grande, erecta hacia el cielo, y tan amplia como para cubrir con su sombra a todos los pueblos toscanos" 3 .

Una serie de miradas y semblanzas pretendo ir concatenando seguidamente; visiones y reflexiones sobre esta insigne obra, consumada expresión, en todos los sentidos y a todos los niveles, de los inicios del arte de la Edad Moderna, en el contexto de la Florencia quattrocentesca que, en un continuum desde el Trecento, alcanzará la cúspide de la cultura artística ensamblando civilidad y humanismo. Resulta lícito considerar a esta cúpula brunelleschiana -aunque no la única- como un detonante y referente de la rinascita all'antico y asimismo una "obra-frontera" que, al tiempo que culminaba la construcción de la Catedral, constituyó un referente cuya sombra, insistiendo en el dicho albertiano, tuvo un recorrido bastante más amplio y que, con mucho, sobrepasó a los puebles toscanos.

Sobre la citada alabanza de Alberti a Brunelleschi y su Cúpula, conviene hacer algunas matizaciones; por una parte, mediada la década 1430-1440, y muy probablemente ese año de 1436 - eje y punto focal de estas reflexiones- con la cúpula ya construida, las tensiones, "enfrentamientos", desencuentros y todo tipo de disparidades con Ghiberti y otros maestros de obras, pero también con los responsables de la fábrica nominados por el Arte de la Lana, gremio a cuyo cargo estaba confiada la

2 Vid. la Addenda con un extracto del texto del motete, al final de estas consideraciones; los destacados son míos.

3 Muy probablemente de 1435 que al año siguiente, y en latín, complementará y perfilará en su De pictura, ya sin esta dedicatoria. La cita exacta es: "Chi mai si duro o sì invido non lodasse Pippo architetto vedendo qui struttura si grande, erta sopra e' cieli, ampla da coprire con sua ombra tutti e' popoli toscani, fatta sanza (sic) alcuno aiuto di travamenti o di copia di legname, quale artificio certo, se io ben iudico, come a questi tempi era incredibile potersi, così forse appresso gli antichi fu non saputo né conosciuto?". 
conclusión de las obras catedralicias, eran ya cuestiones pasadas y, por parte de Brunelleschi, superados de tal modo que entonces su prestigio y consideración eran muy grandes. Atrás habían ido quedando las tensiones y retos que fueron pulsando, desde 1417-1418, la profesionalidad e intelecto brunelleschianos, para ir solucionando los complicados problemas constructivos, en ocasiones mediante audaces propuestas. Eran cuestiones bastante ajenas entonces para Alberti, con lo cual su testimonio se nos presenta como más fidedigno, si bien no gratuito en relación con sus propios intereses e investigaciones ${ }^{4}$, ante todo centradas en un continuado estudio de las ruinas romanas y su directa comprobación en la propia Ciudad Eterna ${ }^{5}$. Debió de impresionarle y mucho la contemplación de los blanquísimos nervios marmóreos, ya previstos para centrar la visión en la aún inexistente linterna ${ }^{6}$, muy destacados en un todo rojo latericio, con ladrillos ensamblados en spinapesce u opus spicatum, que podía verse en cualquier edificio romano, pero nunca en una cubierta de grandes dimensiones. El bicromatismo brunelleschiano, en general gris de la pietra serena-blanco de cal, aparece aquí como blanco sobre rojo aunando visión y perspectiva en y sobre la ciudad, potenciando y destacando, como claves de su dicción artística, un certo ordine di membri e d'ossa molto evidentemente, esto es, elementos estructurales a lo romano, entendidos como "miembros y huesos" parafraseando lo que comentará a posteriori la Vita ${ }^{7}$.

Desde la ampliación de Arnolfo di Cambio, fines del siglo XIII, sobre la modesta iglesia de Santa Reparata y la muy considerable amplificación de Francesco Talenti, mediados del siglo XIV, que supuso sobredimensionar la cabecera del templo, la catedral de Florencia, que asumió la advocación de Santa Maria del Fiore, no sólo fue adquiriendo, en tan dilatado tiempo, un rango primigenio y referente de la ciudad, sino que al unísono de su carácter religioso llegó a convertirse como edificio, o sea como arquitectura o monumento, en un auténtico umbilicus urbis ${ }^{8}$, conformando un

4 Battista degli Alberti, apodado Leon por la fiereza intelectual que marcó y condicionó toda su vida, y florentino "hasta la médula", interesado por entonces en todo tipo de estructuras portantes (léase el Templo de Minerva Médica, inicios del siglo IV d. C., en realidad un ninfeo de los Horti Liciniani), así como respecto a secuencias de arcos y soportes conformando toda suerte de logge y lecturas efectuadas sobre ruinas de acueductos romanos, debió quedar literalmente impresionado por obras florentinas de Brunelleschi como la CÚPULA y el audaz Pórtico del Spedale degli Innocenti.

5 Semejantes a las realizadas por Brunelleschi en sus estancias romanas, entre 1404 y 1417-1418; al respecto vid. BORSI, Stefano: "Dalla sconfitta delle Porte del Battistero all'impressa della Cupola", en Brunelleschi. Florencia, Giunti, 2007, pp. 14-31. A las mismas se alude en la Vita, pp. 63-68 [vid. infra, nota 7]

6 Concluida ya fallecido Brunelleschi, en 1461, es asimismo de mármol blanco y el elemento más ortodoxamente clasicista del conjunto.

7 Simplemente Vita, por brevedad y comodidad, alude a una biografía del artista, muy probablemente escrita por Antonio di Tuccio Manetti a fines del Quattrocento y quedó manuscrita (Vita di Filippo di ser Brunellesco), se cita por Antinio Manetti. Vita di Filippo Brunelleschi, a cura di Carlachiara Perrone. Roma, Salerrno Editrice, 1992; la reseña corresponde a la p. 64 y, corroborando y abundando en lo dicho, se afirma aquí: “... s'è dato precetto, come ne nostri dí fece Batista (sic) degli Aberti” (Vita, p. 68)

8 Verdaderamente esto no es exacto, ya que Florencia era una ciudad policéntrica aunque muy jerarquizada, y sus diferentes quartiere, núcleos zonales o barrios, poseían una suerte de autonomía; no obstante, la importancia y significación del Duomo y su proyecto constructivo, hacen lícito el uso del citado término umbilicus urbis. 


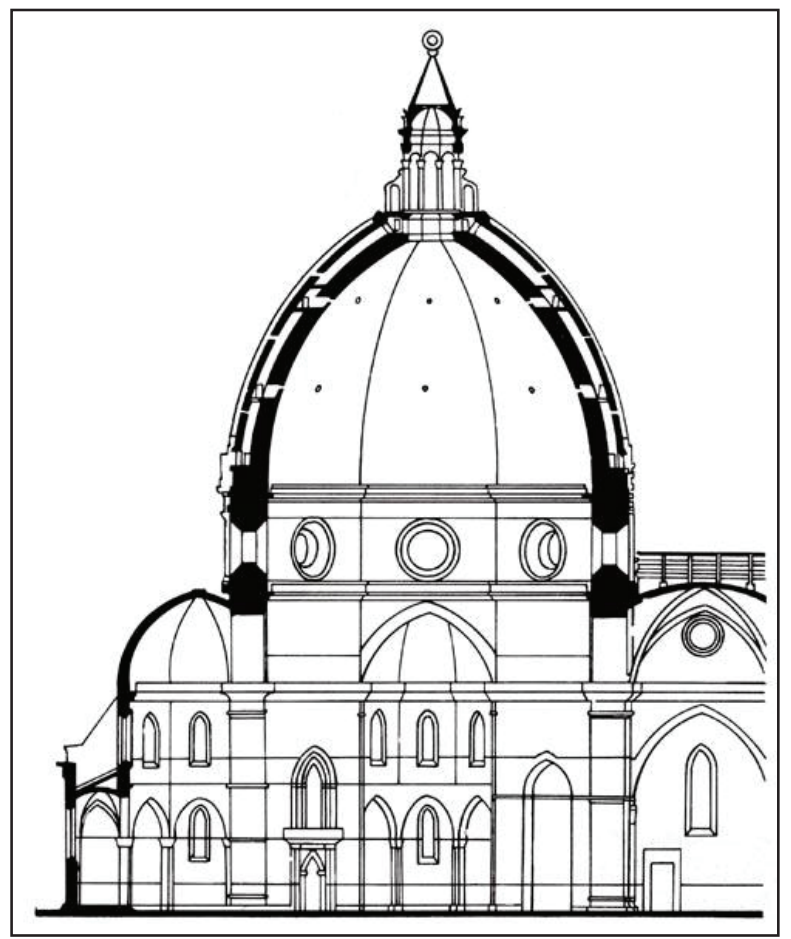

Fig. 2. Cúpula brunelleschisna, sección-esquema.

entorno, con el Baptisterio (il Bel San Giovanni entonces) y su torre (il Campanile di Giotto), que viajeros del siglo XVIII calificaban como un Bel Teatro.

El tambor octogonal con sus óculos quedaba dispuesto como base de la cúpula, c. 1410-1413; una estructura relativamente endeble incapaz de soportar los empujes laterales de una construcción hemiesférica. Si ambicioso y continuamente ampliado durante más de un siglo, había sido el proceso constructivo de la catedral florentina, el reto que asumió Brunelleschi era acaso aún más exigente, y lo fue a varios niveles. Por un lado asumir la necesidad de una estructura apuntada, digamos formalmente gótica -de ahí la idea reseñada de "obra-frontera"-, y así disminuir los aludidos empujes horizontales y bajarlos de nivel para su conveniente contrarresto ${ }^{9}$, liberando el tambor al respecto y, por otro lado, diseñar las oportunas centine o bases de apoyo provisionales, así como ingenios tipo grúas para ir elevando los materiales necesarios; dadas la envergadura y dimensiones de la cúpula, el reto en su momento fue enorme. (Figs. 2-3)

9 Mediante tres grandes ábsides poligonales y los consiguientes “absidiolos" (tribune en nomenclatura italiana); estas últimas serán varias y amplias, unas actuantes, constructivamente hablando, pero también tribune morte, entre las cuales fue proyectado el correspondiente ballatoio o fachada que dignificaba el entorno urbano; una vez más, quedaba previsto un esmerado revestimiento exterior en función de la trascendencia urbana, por más que esta cuestión quedara inconclusa. 
Aún así, el arquitecto procuró, en lo posible, la ligereza de la obra no sólo en base al ladrillo, sino mediante dos cúpulas, una interna maciza, otra externa más sutil y cuidada, y entre ambas un espacio vacío ${ }^{10}$. Casi veinte años hasta su conclusión, el muy reservado talante brunellechiano, las dudas concitadas en el entorno de la obra y las soluciones, han potenciado los aspectos técnico-ingenieriles de la obra, desde mi punto de vista de modo excesivo, sobre los genuinamente arquitectónicos y artísti$\cos ^{11}$. Técnica constructiva obviamente sí, pero no sólo; en efecto, poco se alude a las bases y fundamentos geométricos precisos al respecto y a la relación de Brunelleschi con Paolo dal Pozzo Toscanelli (Florencia: 1397-1482), matemático, astrónomo y cosmógrafo, "maestro Pagolo mattematico e medico, dal Pozzo Toscanelli", como se le mencionaba entonces ${ }^{12}$.

Teniendo presente siempre la referencia de obra-frontera, de manera laxa y sin forzados encorsetamientos, querría insistir en su condición de obra absolutamente paradigmática, de significación y sentidos urbanos muy importantes ${ }^{13}$ y con anclajes en varios referentes previos, que ni minusvaloran la construcción ni la labor de su arquitecto Filippo Brunelleschi, que aceptó y resolvió el gran reto de esta construcción; reto que, en función de su envergadura y dimensiones, es preciso leer y valorar desde una íntima interconexión arte-arquitectura-técnica, siempre consideras al unísono ${ }^{14}$.

\title{
Addenda (Extractos del texto del Nuper rosarum flores de Guillaume Dufay, 1436)
}

\author{
Nuper rosarum flores \\ Ex dono pontificis \\ Hieme licet horrida
}

10 Cúpula interna: 45,5 mts. de diámetro; la externa: 54,8 mts.; espacio vacío entre ambas: 1,20 mts.; base de la cúpula a $55 \mathrm{mts}$. del suelo.

11 Del mismo modo, las nuevas tecnologías, ante todo mediante repertorios de imágenes espectaculares de la cúpula, han logrado, de algún modo, una cierta minusvaloración del resto de la obra brunelleschiana.

12 Vita, p. 69; Vasari, por su parte (Vite, 1550, ed. Torrentiniana), afirmaba que Brunelleschi "imparò la geometria da lui", al que consideraba "un nuovo Santo Paulo". Ha sido destacada la generosidad de Toscane1li, que "donando agli altri il risultato delle sue ricerche. Così con Niccolò da Cusa, così col Müeller [o sea, il Regiomontano], cosi domani con Colombo, cosi ieri col Brunelleschi” (GARIN, Eugenio: Rittratto di Paolo dal Pozzo Toscanelli, incluido en Rittratti di umanisti. Florencia, Sansoni, 1973, pp. 41-66; la cita en p. 59.

13 Parece claro que Brunelleschi era perfectamente consciente de construir en y para Florencia y, en este sentido, "bastaban" los señalados "miembros y huesos" all'antico de connotaciones clasicistas, deducidos en sus "estudios" efectuados en Roma (seguramente el denominado templo de Minerva Médica y el Pantheon -cúpula de 43 mts. y óculo de 8 mts.- y deducir soluciones constructivas al efecto), como asimismo quedó dicho; por lo demás, el contexto florentino de entonces, tan laico como religioso, "casi requería" citas propias y previas. Vid. Brunelleschi, a cura di Attilio Pizzigoni. Bolonia, Zanichelli, 1993 (5ª reimpresión), "1418/ 1436. Cupola di Santa Maria del Fiore. Firenze, Duomo”, pp. 28-43; “1436. Lanterna di Santa Maria del Fiore. Firenze, Duomo”, pp. 140-147 y “1438. Tribune morte di Santa Maria del Fiore. Firenze, Duomo”, pp. $148-153$.

14 Según lo dicho, no se entienden determinadas afirmaciones de Piero Sampaolesi (1904-1980), perfecto conocedor de la cúpula brunelleschiana o, en cualquier caso, deben darse por superadas, al insistir en su relación con la del Mausoleo de Soltaniheh, 1302-1312, en Irán; en éste, la base de su cúpula no era el "debil" tambor florentino y su diámetro de $25,5 \mathrm{mts}$., menos de la mitad de la obra florentina; por lo demás, como solución constructiva sí sintonizan ambas obras. 
Tibi, virgo coelica,

Pie et sancte deditum

Grandis templum machince (...)

Hodie vicarius

Jesu Christi et Petri

Successor Eugenius

Hoc idem amplissimum

Sacris templum manibus

Sanctisque liquoribus

Consecrare dignatus est.

Igitur, alma parens

Nati tui et filia,

Virgo decus virginum

Tuus te, Florentice

Devotus orat populus,

Ut qui mente et corpore

Mundo quicquam exorarit, (...)

Como quedó reseñado, trataré ahora sobre aspectos de Paolo di Dono, detto Paolo Uccello (1397-1475) y su obra, en un intento de plasmar una síntesis válida y coherente en su contexto.

\section{Uccello, consideraciones y parámetros globales}

[Un arte] ... que no se basa como el de Masaccio sobre una certeza revolucionaria, la dignidad del hombre, el naturalismo y la objetividad matemática de la perspectiva brunelleschiana; ... [la aportación de Uccello] en cambio, es problemática, sofistica, continuamente variable, abstracta en su "fantasear" y por lo tanto abierta a lo fantástico; y que, siendo todavía sus bases culturales las medievales, mientras por una parte lleva adelante una experimentación extremista y casi ab absurdo de las búsquedas contemporáneas, por otra no reniega completamente, ante la nueva verosimilitud naturalista, del viejo mundo gótico, de sus fábulas y de sus encantos.

Luciano Berti ${ }^{15}$.

Donatello, según parece, le reprochó precisamente el "dejar lo cierto por lo incierto”. Y así vemos que Uccello no sigue, por ejemplo, la perspectiva artificialis, es decir, el método perspectívico coherente pero artificial inventado por Brunelleschi; sino que profundizará, por el contrario, en la perspectiva naturalis, es decir, en la óptica investigada ya sutilmente en el Medioevo (Alhazén, Bacon, Vitellone) ${ }^{16}$, sobre la cual,

15 Paolo Uccello, 1954; reseñado en TONGIORGI TOMASI, Lucia: "Paolo Uccello. Antología de interpretaciones críticas", en La obra pictórica completa de Paolo Uccello. Barcelona, Noguer-Rizzoli, 1977, p. 14; los destacados son míos.

16 Se trata respectivamente de: Ibn al-Haytam (965-1039), Roger Bacon (c. 1214-1294) y Vitellonis Thuringopoloni (c.1230-c.1290; en cualquier caso: post. 1280 y ant. 1314), vid. [Addenda: Alhacén, Bacon,Vitellone] inmediatamente tras las consideraciones sobre Uccello. 
por su rivalidad con Brunelleschi, prefería basarse también en la teoría de Ghiberti, maestro de Paolo.

Luciano Berti ${ }^{17}$.

Pretendo aquí trazar un perfil coherente de Paolo Uccello y su obra, su importancia, significación y singularidad en el desarrollo de la pintura florentina del Quattrocento; me he impuesto este reto a pesar de no ser tarea fácil, en pro de clarificar su personalísima y compleja trayectoria, así como sus sugestivas opciones que rompen cesuras y eliminan compartimentos estancos -al menos entre los siglos XIV y XVen los inicios del arte de la Edad Moderna. Asumo como referencias básicas dos excelentes estudios al efecto de Padoa Rizzo ${ }^{18}$ y Stefano Borsi ${ }^{19}$, ambos importantes y clarificadores, a mi juicio, $\mathrm{y}$, al tiempo, rigurosos y fascinantes en sus respectivas inmersiones en el universo uccelliano.

Los juicios peyorativos vertidos por Giorgio Vasari en la segunda mitad del siglo XVI, proyectaron una alargada sombra negativa a propósito de la valoración del arte de Uccello, un tanto olvidado y postergado hasta el siglo XIX; en efecto, en sus Vite (tanto en la edición de 1550 como en la de 1568) el aretino, aunque destaca el talante investigador y la capacidad de trabajo de Paolo, le reprocha su excesivo interés por sistemas de visión ajenos a la racionalidad de una perspectívica unitaria, cuestión ya "impuesta" desde el legado Brunelleschi-Masaccio-Alberti, sus planteamientos y lenguaje "fantástico", opuestos al "naturalismo esencial" del pintor valdarnés que, en su opinión, le habría conducido al descuido de una coherente figuración. En otras palabras, y como no podía ser de otro modo, en pleno Cinquecento, Vasari "no entiende" -no quiere y/ o no puede entender- las aportaciones de Uccello. Al calor de vanguardias históricas del siglo XX, casos del Cubismo y Surrealismo, a mi entender, en un proceso no ajeno a la progresiva comprensión y valoración de Piero della Francesca, fue justipreciándose $\mathrm{y}$, de algún modo, comprendiéndose y poniendo en valor la pintura de Uccello $^{20}$, hasta las fundamentales aportaciones al efecto, desde la cuarta década del siglo, de Alessandro Parronchi ${ }^{21}$. Arribamos de este modo a las

17 "Dotado por la naturaleza de un talento sofístico y sutil", epígrafe que utiliza, en su monografía, el reclamo de este juicio vasariano [según traducción de las Vite, 1568] en Paolo Uccello. Buenos Aires, Editorial Codex, 1965, pp. 3-4; el destacado es mío; [ . . eccellente pittor fiorentino, il quale perch'era dotato di sofistico ingegno, si dilettò sempre di investigare faticose e strane opere nell'arte della prospettiva., en VASARI, Vite. Florencia, edición Torrentiniana, 1550; cito por Giorgio Vasari. Le vite de 'più eccellenti architetti, pittori, et scultori italiani, da Cimabue insino a 'tempi nostri. Nell'edizione per i tipi di Lorenzo Torrentino. Firenze, 1550. A cura di Luciano Bellosi e Aldo Rossi. Presentazione di Giovanni Previtali. Turín, Einaudi, 1991, volume primo, p. 236; en adelante: Vasari, 1550]

18 PADOA RIZZO, Anna: Paolo Uccello. Catalogo completo dei dipinti. Florencia, Cantini, 1991; en adelante, simplemente Padoa-Uccello.

19 BORSI, Stefano: Paolo Uccello. Florencia, Giunti, 1992; en adelante, simplemente Borsi-Uccello.

20 Ya en fechas inmediatamente anteriores a la Primera Gran Guerra, lo hacía Roberto Longhi, de manera no tan contundente como en el caso de la Officina Ferrarese y Cosmè Tura, pero sí como muy significativo acicate para los fundamentales estudios de Alessandro Parronchi.

21 Ante todo, vid. PARRONCHI, Alessandro: "Paolo Uccello" en Enciclopedia Universale dell'Arte, vol. X. Venecia-Roma, Istituto per la Colaborazione Culturale, 1963 e idem: Studi su La Dolce Prospettiva. Milán, Aldo Martello Editore, 1964 (sobre todo “La 'Visione dell'occhio' secondo il Ghiberti”, pp. 313-348, que pone en preciso contrapunto con "Le due tavole prospettiche del Brunelleschi”, pp. 226-295) 


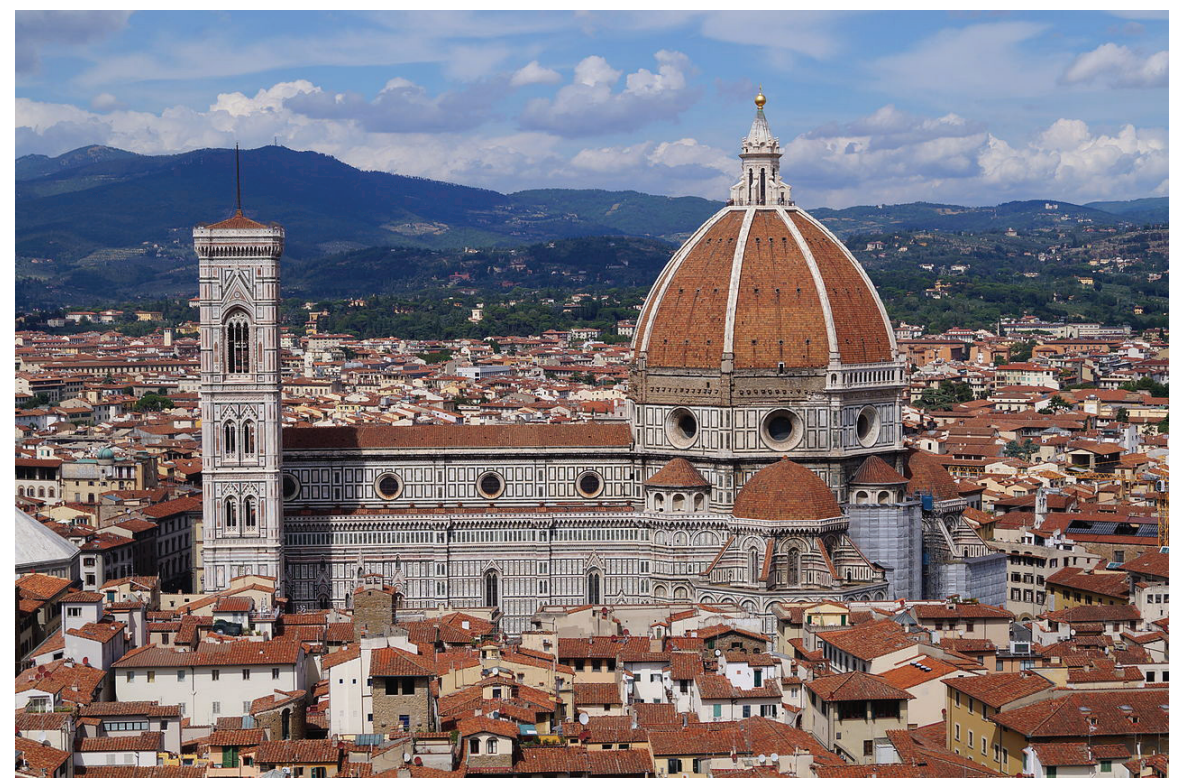

Fig. 3. Conjunto de Santa Maria del Fiore, Florencia.

sugestivas y penetrantes afirmaciones de Luciano Berti, según se colige de las citas utilizadas como inicio de este acercamiento a la creatividad artística y, nunca mejor dicho, a las sutiles y sofisticadas "puestas en escena" de Paolo Uccello, en muchas ocasiones con unas composiciones aplicadas al entorno visual y mediante unos entramados "verdaderamente arquitectónicos".

Para el que esto escribe -en más de una ocasión lo he hecho constar- Luciano Berti, al menos cuando incide en el primer Quattrocento florentino, parece superarse a sí mismo, agudizar su ingenio y plasmar de modo claro, sintético y certero, las claves precisas que validan y definen la figura y obra del artista que trata; lo evidencian de manera contundente y resultan elocuentes per se, las citas que preludian este trabajo $^{22}$. Son acaso las mejores líneas a seguir y, por ello-destacados incluidos- he optado aquí por incidir en ellas y así conformar una suerte de urdimbre que sirva de coherente base y fundamentado cimentaje a este acercamiento a Uccello ${ }^{23}$.

22 Citas que quieren ser también un recuerdo-homenaje a este gran historiador del arte que tanto contribuyera a los estudios sobre Masaccio, entre otros muchos. L. Berti (Florencia: 1922-2010)

23 Sobrenombre o mote asignado ya coetáneamente al artista -uccello, pájaro en italiano- por su intervención en las Puertas Norte de Ghiberti en el Baptisterio de la catedral de Florencia, en cuyos enmarques plasmó Uccelo magistralmente -bajo diseños ghibertianos y curiosamente con un acendrado naturalismo- toda una serie de elementos fitomórficos, muy en particular pájaros. Son éstas las puertas de bronce sobredorado (el plural alude a sus dos batientes) que devienen del célebre Concurso de 1401 (al respecto, vid. SUÁREZ QUEVEDO, Diego: “Centenario del concurso de 1401 para las puertas del baptisterio florentino", Anales de Historia del Arte, 13 (2003), pp. 308-315); en la actualidad, y desde marzo de 2013, en proceso de restauración y rehabilitación, habiendo sido desmontadas de su locus habitual. 


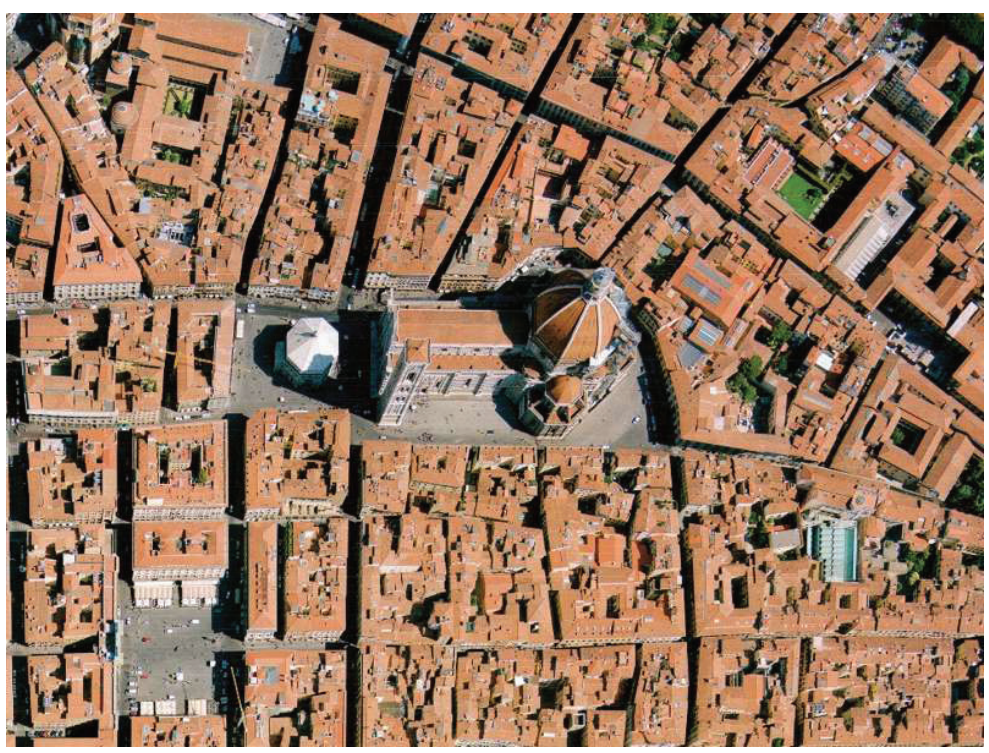

Fig. 4. Santa Maria del Fiore, vista aérea.

La idea de una trayectoria artística personalísima y, en buena medida, a contracorriente de lo que podríamos considerar "vanguardia" del momento, quedan fehacientemente explicitadas; "vanguardia", entendida como las propuestas artísticas que, en su espacialidad, composición y perspectiva, se adaptan o tratan de hacerlo de manera clara a los planteamientos que devienen de las celebérrimas tavolette brunelleschianas $^{24}$, esto es la denominada perspectiva artificialis.

Resulta clara, respecto a Uccello, la cuestión del magisterio de Lorenzo Ghiberti; bajo directrices de éste e integrado en su prestigioso taller laboró (se le hace constar ya en 1407) durante la larga gestación de las segundas puertas (primeras de Ghiberti, 1404-1424) del Bel San Giovanni, como entonces era denominado el baptisterio florentino. En este ámbito profesional, c. 1408, coincidió con Donatello, con el cual mantuvo una amistad continuada ${ }^{25}$, aunque este último siga otros derroteros muy diversos, muy alejados de la perspectiva naturalis que llegó a obsesionar y fascinar,

24 Anteriores seguramente a 1412-1413; planteamiento puesto en evidencia, c. 1427-1428, por Masaccio sobre todo en La Trinidad de Santa Maria Novella, y que quedará codificado por Alberti en sus De Pictura y Della Pittura (redactados c. 1435-1436). En relación con las citadas tavolette, vid., Vita, op. cit., pp. 53-58; y como apurada síntesis, vid. Brunelleschi, a cura di Attilio Pizzigoni, op. cit., pp. 24-27 ("Le tavolette prospettiche. L'intuizione razionale dello spazio"; tavolette que, en cambio, son datadas en 1415)

25 Según Vasari "Fu condotto Paulo [sic; Uccello] da Donato [Donatello] a Padova, quando vi lavorò; e vi dipinse nell'entrata della casa de'Vitali [sic; Vitaliani], di verde terra, alcuni giganti, che ... sono tanto belli, che Andrea Mantegna ne faceva grandissimo conto"; dato no incluido en Vasari, 1550 y sí en la edición giuntiniana de las Vite (Florencia, 1568), cito por Milanesi tomo secondo, p. 214 (en adelante, Vasari, 1568) Donatello en Padua (1443-1453). Se trata de "i perduti Giganti di casa Vitaliani, un ciclo monocromo di "uomini illustri" ... (Borsi-Uccello, p. 32, que, no obstante afirma que "Paolo si reca nel 1445 chiamatovi, secondo Vasari, da Donatello") 
en sintonía con la postura antibrunelleschiana de Ghiberti, a Uccello que abandonó lo cierto por lo incierto.

Es más, resulta lícito considerar lo cierto como lo icástico y, en general, algo ajeno a Uccello, que sí insiste y se recrea en lo incierto o fantástico, interesado y "anclado" en formulaciones culturales medievales, con una notoria tendencia a la abstracción que va ser clave en sus últimas obras. No obstante, mediante una continuada experimentación que roza aspectos casi $a b a b s u r d o$, respecto a planteamientos contemporáneos, y todo ello en aportaciones exquisitamente sofisticas, o sea de muy cuidadas y elaboradas sutilezas que, en determinadas ocasiones, no eluden intenciones y logros francamente caricaturescos o acaso calificables de extravagantes ${ }^{26}$.

Desde unas coordenadas globales y con variantes continuas, el uso de la perspectiva naturalis -abuso diría Vasari- por parte de Uccello, le conduce, en general, a planteamientos no unitarios en un continuado proceso de experimentación, con ideaciones y visualizaciones diversas que lo mismo definen espacios no racionalmente mensurables que presentan una profundidad ad infinitum, y donde figuras e historias aparecen a menudo en claves de fantasiosas fabulaciones. Varios puntos de vista, composiciones ajenas a una armonía proporcionada, acusado contraste de escalas de figuras y elementos, así como antagónicos planos de visión tanto en altura como en profundidad; con altísimas calidades pictóricas se plantean reflexiones de la visión - desde variadas superficies especulares- cuyas deformaciones se adjuntan y/ o complementan las escenas ${ }^{27}$.

El interés por el color en sí mismo o la íntima conexión forma-color en sutil sín$\operatorname{tesis}^{28}$, fueron fundamentales en las investigaciones y experimentaciones de Uccello respecto a la citada perspectiva naturalis y, en su momento apreciada y valorada, como se colige del siguiente epigrama que, entre otros varios -tanto en latín como en vulgar según Vasari ${ }^{29}$ - fueron redactados a su muerte:

"ZEVSI E PARRASIO CEDA, E POLIGNOTO,

CH'IO FÉ L'ARTE VNA TACITA NATVRA:

DIEI AFFETTO E FORZA AD OGNI MIA FIGVRA,

VOLO A GLI VCCELLI, A'PESCI IL CORSO E'L NVOTO",

No obstante, y sin solución de continuidad, considera el aretino como prioritaria en el arte de Paolo, la que denomina questa dolce prosppettiva; respecto a ésta, parte

26 La mayoría de sus obras, por otro lado, de muy alta calidad pictórica -insisto-, sugestivas, plenas de efectos cambiantes e insólitas concatenaciones.

27 Sobre estas ideas y concepciones escenográficas, volveré luego, ya que a mi entender resultan fundamentales en Uccello, no siendo referenciadas a menudo. Sí incide en la profunda influencia del teatro en Uccello, NIETO ALCAIDE, Víctor: "II, 1: Los elementos del nuevo sistema figurativo: la perspectiva como método científico de representación", en El Renacimiento. Formulación y crisis del modelo clásico. Madrid, Istmo, 1980 y reeds., pp. 75-77.

28 A menudo señalada como "taraceas de color", de algún modo en conexión con el arte del mosaico, que tanto le interesó, como luego señalaré y, en cierta medida con el arte de la vidriera, cuyos diseños forman parte importante de su obra e investigaciones; geometría, especulación intelectual y color se aúnan en pro de su dolce prospettiva.

29 Vasari, 1550, p. 240. 
de una de las anécdotas - de recurrencia constante por los estudiosos de la obra de Uccello- que Vasari incluye en sus Vite, conviene hacer algunas precisiones.

La anécdota o semblanza en cuestión que, con una cierta ironía perversa, es introducida en el párrafo que remata la biografía de "PAULO UCCELLO/ Pittor Fioren[tino]"; es la siguiente:

“... e la moglie, la quale soleva dire che tutta la notte Paulo stava nello scrittoio per trovare i termini della prospettiva, e mentre ch'ella a dormire lo invitava et egli le diceva: 'O che dolce cosa è questa prospettiva'?' ${ }^{30}$.

La perspectiva artificialis que dimanaba del legado Brunelleschi-Alberti y Masaccio-Donatello, era la ponderada por Vasari y, en general, se había impuesto por la racionalidad de su concepción espacial y la rigurosidad de sus fundamentos geométricos; ésta no interesó prioritariamente a Uccello, aunque sí realizó obras de visiónplanteamiento unitario $\mathrm{y} / \mathrm{o}$ de connotaciones perspectívico-escenográficas, acorde con el constante afán investigador que le era innato. La citada perspectiva naturalis de raigambre ghibertiana fue, en cambio, la que más cultivó, ensayó y preocupó al artista, casi como una obsesión, de ahí el aludido sesgo crítico vasariano, aludiendo a questa prospettiva como dolce cosa; optaba Uccello decididamente por un ideal, según los criterios reseñados, de pulchritudo, tanto de raíz anacreóntica como agustiniana $^{31}$, definido por una íntima imbricación forma-color, sus resonancias y reflexiones, para conformar un continuum persuasivo al modo de Ghiberti, que, a menudo Uccello, "contamina" bien de ciertas deformaciones ópticas, bien de determinadas concepciones abstractizantes.

Fascinante y de capriccioso ingegno, Paolo Uccello, solitario, strano, malincolico e povero, en palabras asimismo de Vasari en ambas ediciones de sus Vite, resulta difícil y complejo de perfilar coherentemente en la actualidad; al respecto son muchas las atribuciones y pocas las certezas, obras perdidas, de otras sólo fragmentos y varias tan ilegibles, dado su pésimo estado de conservación, que apenas permiten hacer conjeturas. Entre estas últimas, es digno de mención el conjunto de frescos con Historias de Santos Padres ${ }^{32}$, post. a 1447, en el claustro superior de San Miniato al Monte o el retrato de dama, que denotaba una altísima calidad (pertenecía a la colección Lehman de Nueva York ${ }^{33}$ ), seguramente Battista Sforza duquesa de Urbino, 1465-1468, que contrasta con varios retratos previos, bien es verdad que de dudosa atribución y datación, en torno a la década 1430-1440. Del mismo modo, se le atribuye una producción gráfica importante, en función, según quedó reseñado, de su innato interés por una experimentación constante según sus personales claves e intereses; al mazzocchio sí será preciso aludir. Tras lo comentado, casi se impone que

\footnotetext{
30 Vasari, 1550, p. 241, el destacado es mío; y finaliza señalando que "La quale egli veramente a buono ordine mise in uso, come ancora ne fanno piena fede l'opere sue" (ibidem, p. 241)

31 Pulchritudo vincit, según Anacreonte; Pulchritudo est ordinis, o la idea de belleza según San Agustín.

32 Vid. Padoa-Uccello, cat. 15, pp. 92-105 y Borsi-Uccello, pp. 35-39 .

33 Vid. Padoa-Uccello, cat. 20, pp. 118-119.
} 
sea notoriamente reductivo; las referencias van a ser las mínimas y las que entiendo deben ser precisas ${ }^{34}$.

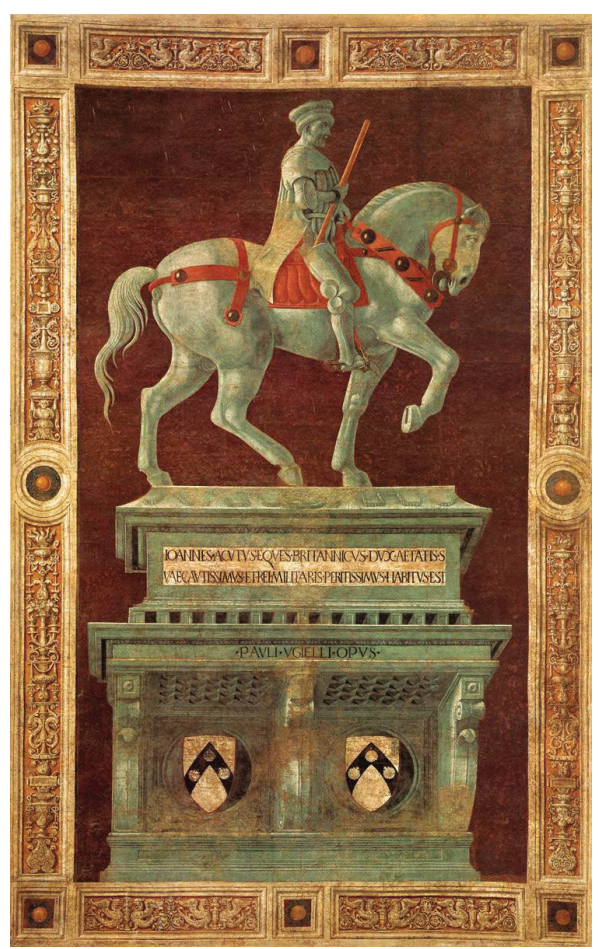

Fig. 5. Uccello, Monumento a Giovanni Acuto.

\section{De los inicios al Acuto y las Batallas}

Pocos y bastante inciertos son los datos a comentar antes del Acuto florentino de 1436; en el taller de Ghiberti desde muy joven, c. 1407, con quien colaborará en las Puertas Norte, concluidas en 1424 e, incluso, en algunos fondos de las posteriores Puertas del Paraiso. Relación continuada y magisterio del insigne maestro, fundamentales para Uccello. Resulta lícito pensar que el propio Ghiberti aconsejase y motivase su traslado a Venecia; aquí estuvo durante el intervalo 1425-1430 interesado por las vidrieras y el mosaico ${ }^{35} \mathrm{y}$, por tanto, ajeno a la eclosión masacciesca (capilla Brancacci del Carmine y Trinidad de Santa Maria Novella); a su regreso a Florencia ya había muerto el pintor valdarnés e incluso Masolino estaba ausente, primero en Roma y luego en Castiglione d'Olona.

\footnotetext{
34 Y salvo indicación expresa, referidas a Padoa-Uccello y Borsi-Uccello.

35 A su regreso a Florencia, será mencionado como "maestro vidriero y experto en mosaicos"; varios diseños se le atribuyen para realizaciones en la propia basílica de San Marcos, donde llegó a diseñar un perdido mosaico de San Pedro para su fachada.
} 


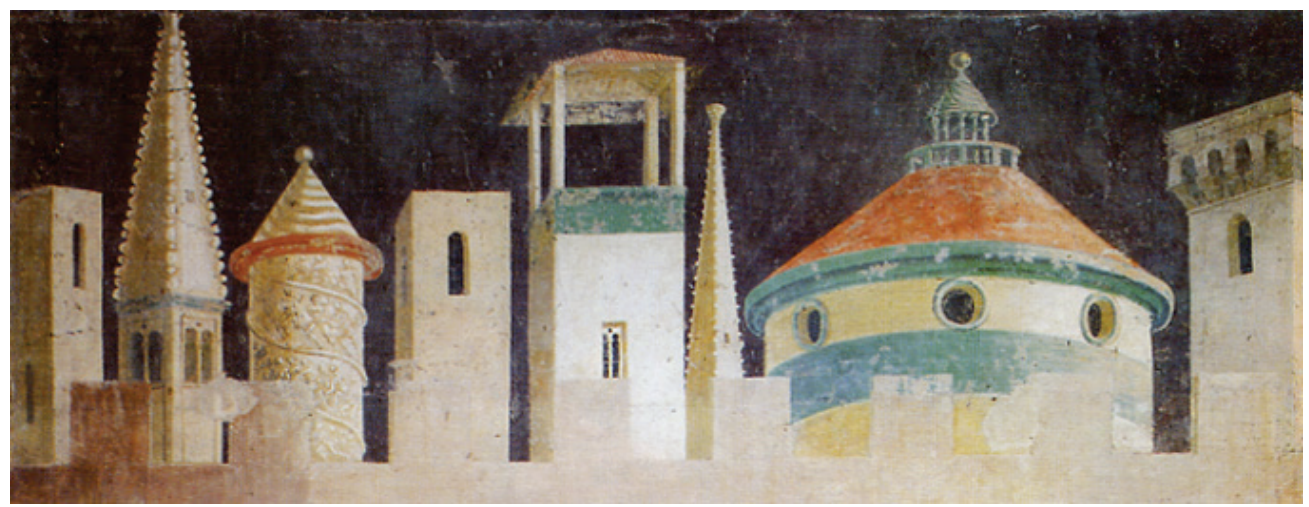

Fig. 6. Uccello, Lapidación de San Esteban, det., catedral de Prato.

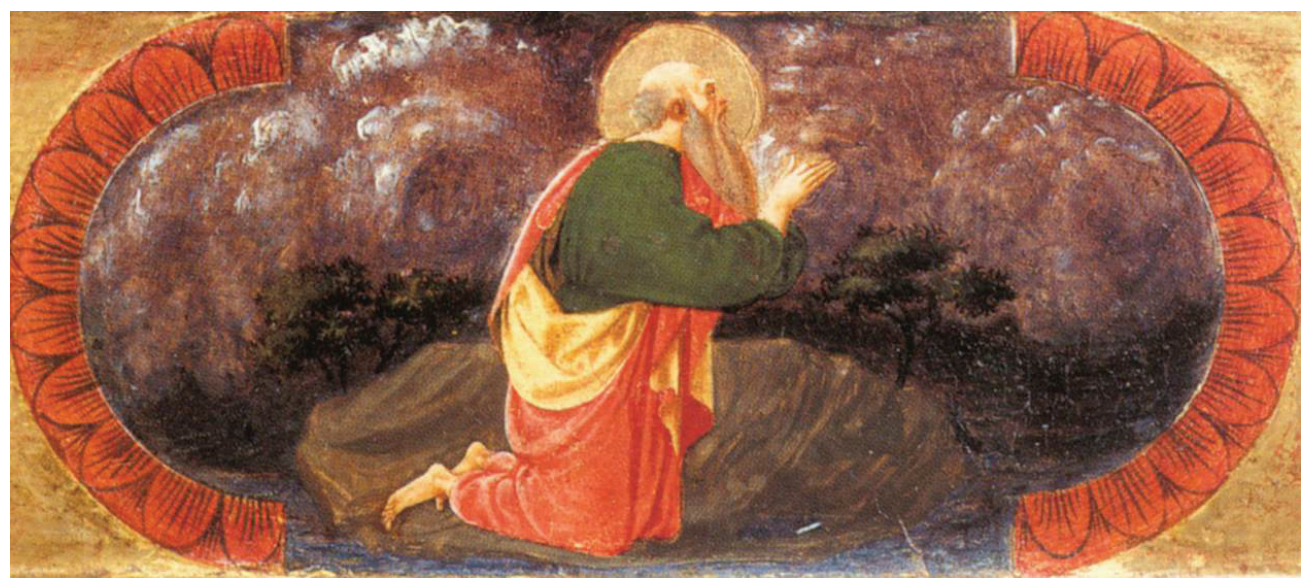

Fig. 7. Uccello, San Juan en Patmos, predella di Quarata, det.

Una primera serie de frescos en el denominado Claustro Verde de Santa Maria Novella, corresponde al parecer al intervalo c. 1431-1433; muy perdida la superficie pictórica y aún de notoria inmadurez, se trata de figuras en grisalla que, sobre propicios fondos oscuros, ilustran los primeros episodios del Génesis que, también al parecer, complementará más tarde.

La intervención de Uccello en los frescos de la Capella dell'Assunta de la catedral de Prato, debe datarse c. 1433-1434. El color adquiere aquí una importancia considerable y, en las arquitecturas voluntariamente extraños, y esto tanto en episodios de la vida de la Virgen como en los dedicados a San Esteban; particularmente interesante son los correspondientes a la ciudad del fondo, de la Lapidación de san Esteban, el resto parece ser obra de Andrea di Giusto, ya que es un insólito "manifiesto brunellesciano". (Fig. 6) 


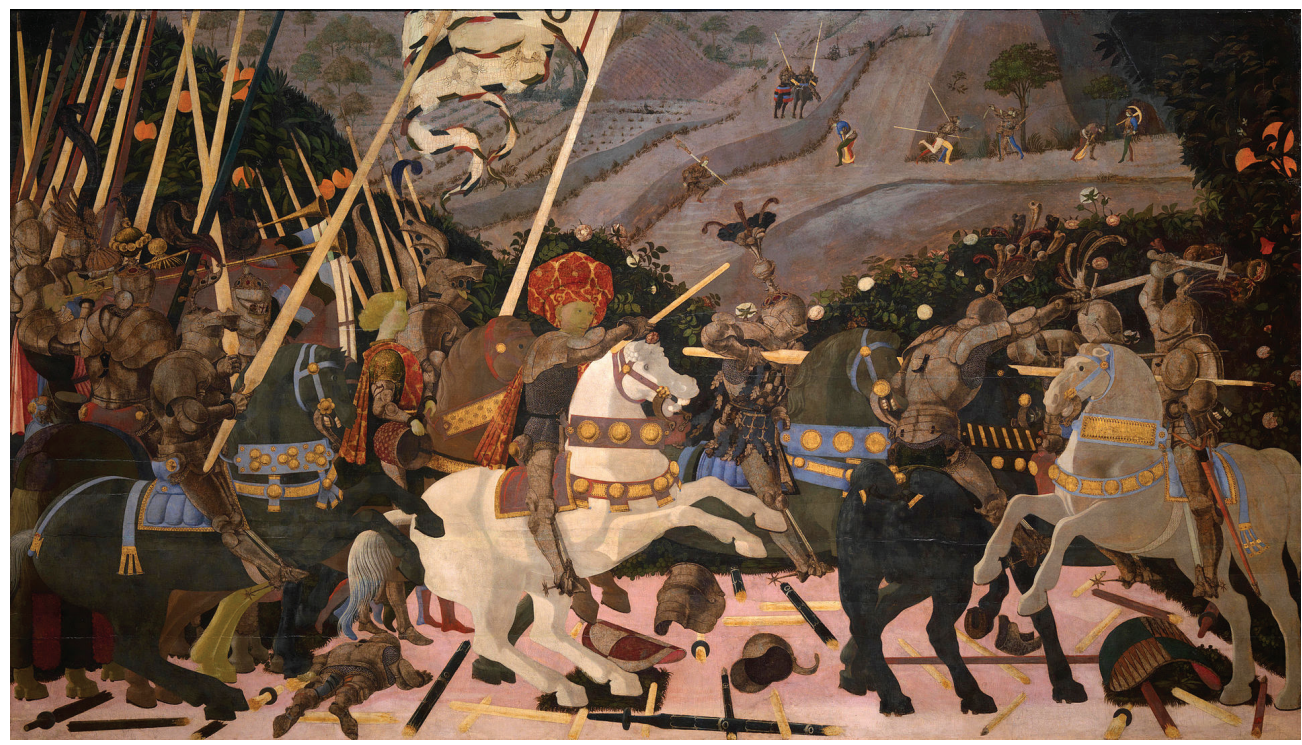

Fig. 8. Uccello, Batalla-Londres.

Aunque sea solamente un fragmento de una perdida pala d'altare, la predella di Quarata, con bastante probabilidad de c. 1435, es ya una obra inmersa en la fascinante y persuasiva poética de Uccello (Fig. 7); tres compartimentos de audaces enmarques ovales, cuyos extremos quedan conformados mediante la sucesión de una suerte de rojos pétalos, un tanto geometrizantes. En el centro y a mayor tamaño, un boscoso nocturno con la Epifanía, lo mismo que a la derecha los santos Santiago y Ansano; a la izquierda san Juan en Patmos, envuelto en unas preleonardesca nubes.

El monumento a Giovanni Acuto, 1436, fue el primer encargo público (Fig. 5) comisionado a Uccello, para lo cual parece haber sido determinante el apoyo dispensado al efecto por Cosme el Viejo de'Medici ${ }^{36}$ y que, orgulloso de su obra ${ }^{37}$, la firmaba en caracteres latinos: PAVLI VGLIELLI OPVS. Realización de un proyecto anterior de fines del Trecento, a colocar en el interior de la catedral de Florencia y, por tanto de carácter funerario y como recuerdo-homenaje al condottiero inglés John Hawkwood,

\footnotetext{
36 Presuponiendo la data de 1435 para el encargo a Uccello de las Batallas por parte de Cosme el Viejo, se insiste en su decisivo apoyo para esta obra (Borsi-Uccello, p. 25); por otra parte, señalando el uso de la terra verde como algo impuesto a Uccello, se alude al fingido monumento broncíneo de connotaciones romanohumanísticas, derivadas de la coetánea traducción de Plutarco llevada a cabo por Lapo di Castiglionchio, lo cual, por relaciones, cercanía y amistad, podría conducirnos al propio Alberti, también para las cuidadosas inscripciones (Padoa-Uccello, cat. 7, pp. 62-63)

37 Para este fresco $(820$ X $515 \mathrm{~cm}$.), realizó Uccello su primer diseño conocido, hoy en los Uffizi; se trata de un cuidado estudio de proporciones y de encuadramiento de caballo y jinete, concebido para un cabal transporte a una escala mayor, según un método desarrollado por Uccello, muy probablemente, bajo indicaciones de Ghiberti.
} 


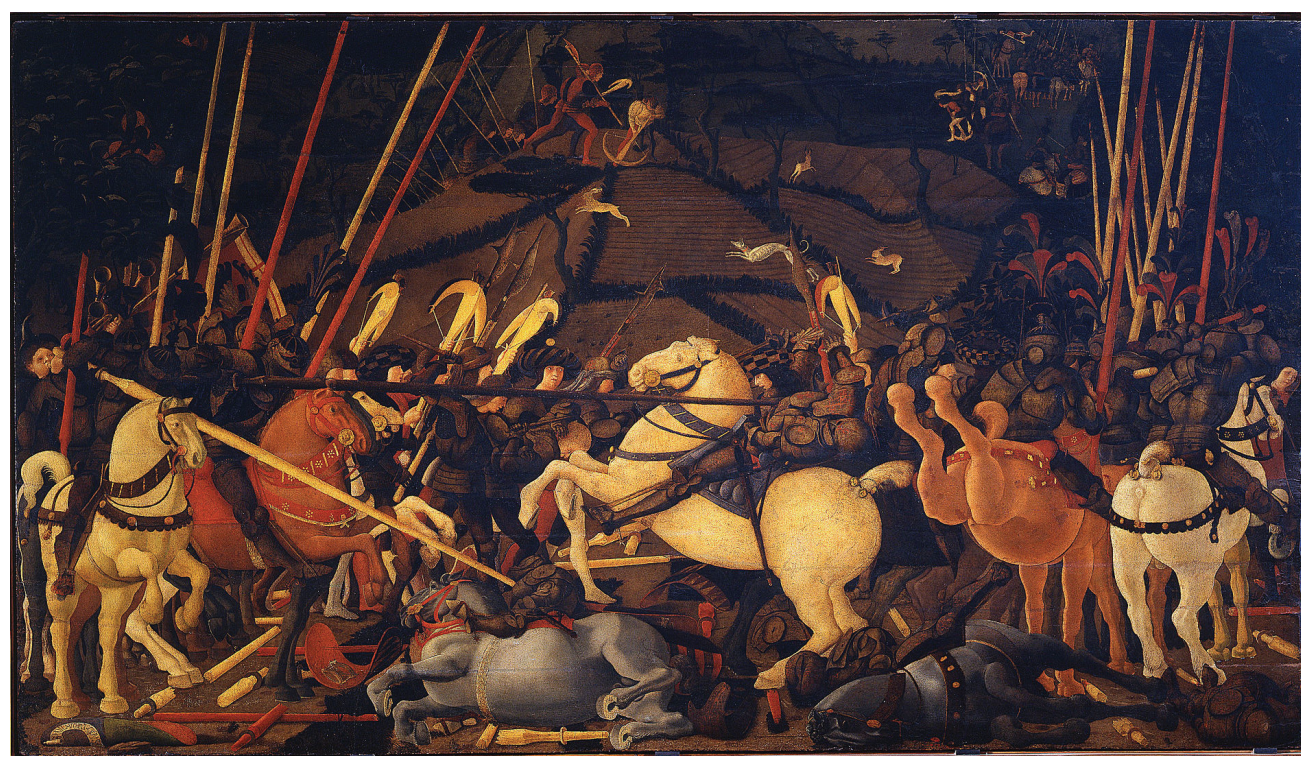

Fig. 9. Uccello, Batalla-Florencia.

fallecido en 1394, por servicios prestados a la Signoria como militar a sueldo ${ }^{38}$; ante todo, pues, con una dimensión cívica, sobre la que incide su carácter ecuestre. Se trata de la primera obra documentada del artista, que recibe varios pagos durante 1436, por una primera versión no aceptada y una segunda rectificada, que se consideraba más digna para las inmediatas celebraciones a realizar en este templo.

Ni se logra ni se pretende un resultado unitario de la visión, sino que es consecuencia de una voluntaria divergencia; una aprehensión en tiempos diversos y ajena a la simultaneidad, por ejemplo, de la Trinidad de Masaccio en Santa Maria Novella (c. 1426-1428), se fuerza así el sotto in su imponiendo un perfil numismático e ideal a caballo y jinete, respecto al sarcófago pintado como basamento ${ }^{39}$, todo con evidentes intentos simbólicos de connotaciones áulicas.

Fundamental en el catálogo de obras de Uccello, es la Battaglia di San Romano, 1435-1440; un unicum en su momento, planteado como una singular escenografía

38 Lo emblemático y el sentido áulico del condottiero de Uccello, contrastaban, en general, con la consideración social de estos personajes en el Quattrocento, tan necesarios, por otro lado, para atender a la defensa de las ciudades-estado italianas. Como "retrato" ecuestre fue el detonante inmediato del Gattamelata que Donatello realizara durante su estancia en Padua, 1443-1453, ya como escultura en bronce y a tamaño monumental, ya fuera del templo y "recuerdos" del Marco Aurelio romano, a su vez, referente del Colleoini de Verrocchio; retratos ecuestres que, tras las contribuciones de Leonardo en su primera etapa milanesa, pasarán a considerarse como representaciones casi exclusivas de y para príncipes, dicho en sentido genérico, A su vez, y justo al lado del Acuto en la propia catedral florentina, debió ser un impulso para el monumento a Niccolò da Tolentino, 1456, de Andrea del Castagno.

39 Se trata de la denominada Costruzzione per cerchio, si bien hay que contar con una colocación del fresco, en su momento, sensiblemente más alta que la actual. 


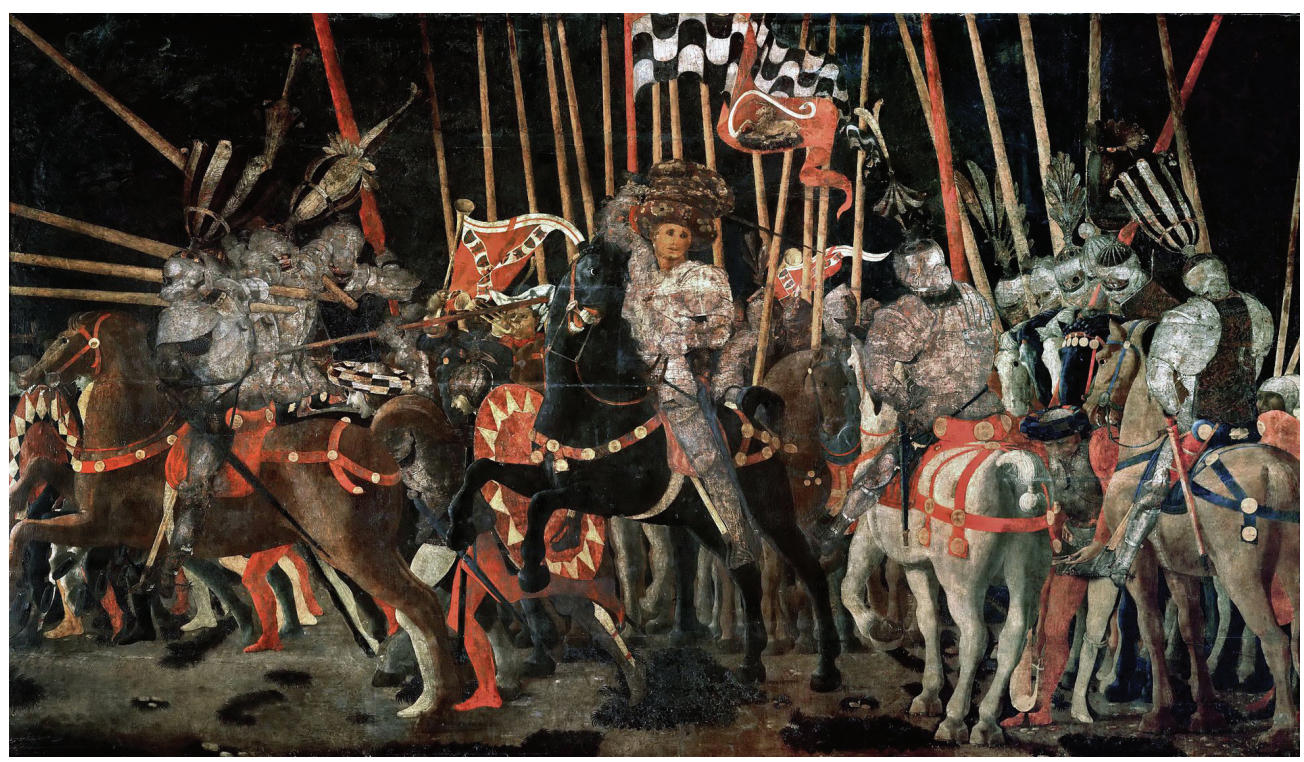

Fig. 10. Uccello, Batalla-París.

teatral ("torneo") y conformado por tres tablas pintadas( Figs 8-9-10), tres momentos, del encuentro bélico ("domingo 1 de junio de 1432" ${ }^{40}$ ) entre tropas florentinas y tropas de Siena, aliada en esta ocasión con los Visconti de Milán. Aunque ha habido otras propuestas, la más aceptada es que dos de los paneles quedaran en secuencia y un tercero en ángulo, considerándose que el central fuera la que hoy se conserva en los Uffizi (firmado: "PAULI UCCELI OPUS"); de dimensiones similares pero no iguales, fueron separados y dispersados posteriormente, suprimiendo en cada uno un medio punto rebajado que remataba superiormente cada episodio, con los presumibles "juegos perspectívicos" tan propios de Uccello. Usualmente se les denomina Batallas ${ }^{41}$ y se asocian a cada una de las ciudades en que actualmente están: Londres, que parece ser la primera, la citada de Florencia, en segundo lugar y la de París como último episodio del evento bélico ${ }^{42}$.

Resultado no contundente de la batalla, ni supuso una victoria militar, pero aseguró, en cambio, la posición y liderazgo de Cosme el Viejo de'Medici en el contexto florentino; lo cual redunda en la idea de encargo de éste a Uccello, incluso como recuerdo del condottiero, que fallecería en 1435, Niccolò da Tolentino muy allegado

40 Vid. Borsi-Uccelo, "Primo giugno 1432. La Domenica di San Romano", p. 23.

41 Ibidem, pp. 13-22.

42 Panel izq., témpera sobre tabla, 182 X 317 cm., National Gallery, Londres: Niccolò da Tolentino al frente de los florentinos; panel central, témpera sobre tabla, 182 X 323 cm., Uffizi, Florencia: "Disarcionamento" de Bernardino della Ciarda, capitán de las tropas de Siena; panel dcho., témpera sobre tabla, 180 X 316 cm., Louvre, París: Intervención de Micheletto da Cotignola [L'arrivo delle truppe guidate dal Cotignola] Padoa-Uccello, cat. 9, 10 y 11, pp. 66-81. 


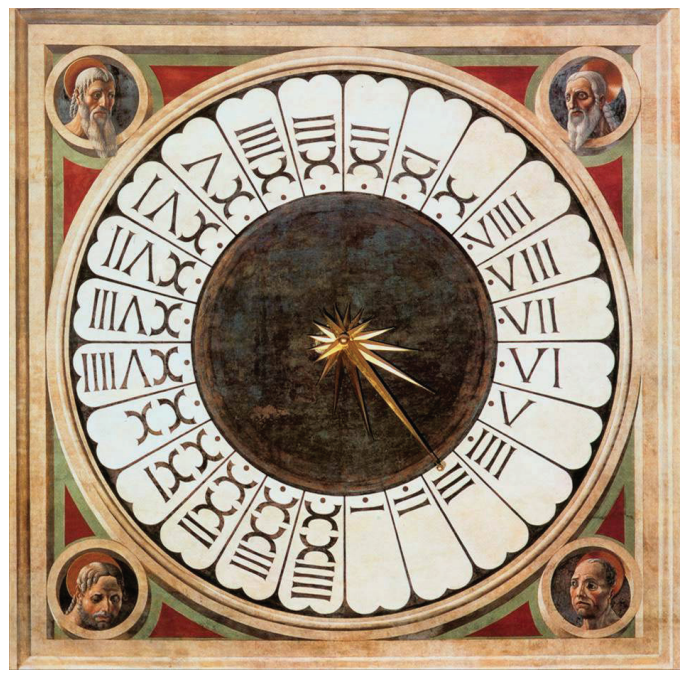

Fig. 11. Uccello, Cuadrante horario, contrafachada catedral de Florencia.

a Cosme, en tanto que Cotignola lo era a Averardo de'Medici, cuya muerte en 1434, consolidaría al "Gran Mercante", como gustaba ser llamado a Cosme.

El drama se nos presenta silencioso y congelado en primer plano, como "recortado" sobre una naturaleza "inmóvil" y extraña; predominan los elementos heráldicos y los capitanes presentan actitudes destacadas, pero con un aspecto melancólico y ensimismado. Durante un tiempo las pinturas fueron documentadas, como ya he reseñado, giostre, es decir torneos, y debemos imaginarlas con los medios puntos rebajados sobre cada una de las secuencias; incluso sin éstos las Batallas exhiben un vivaz interés de Uccello por los fenómenos ópticos y por los problemas particulares de la visión derivados de Ghiberti ${ }^{43}$, aquí culminados mediante un personalísimo desarrollo por parte de Paolo, que no insiste en una exaltación fácil de los vencedores y cada uno de los episodios de la batalla, como congelado y ajeno a toda consideración temporal, parece más bien desarrollarse entre autómatas que actúan sobre una suerte de proscenio, conformando, en tres momentos, una auténtica metafísica de la batalla histórica.

La contemplación de las tablas evidencia una gran riqueza matérica, de refinados juegos y reflejos, potenciados mediante hojas de oro y plata sobre la superficie pictórica, en general muy perdidas pero aún visibles en la tabla de París, la mejor conservada; en todas, se aúnan colores irreales en los primeros planos y un renovado sentido de abstracción en los fondos, proporcionando una calculada visión entre personajes paralizados en sus acciones, armaduras metálicas y lanzas ${ }^{44}$.

43 Que dedica su Terzo Commentario (c. 1448-1452), como es sabido, a reflexionar sobre la perspectiva naturalis; ¿podría adjuntarse a los mismos un interés de Uccello por determinadas soluciones de Pisanello?

44 Una Cabeza de hombre con turbante, conservada en los Uffizi, es un estudio previo para la cabeza de Niccolò da Tolentino; como giostre, figuraban en el inventario, 1492, de Lorenzo el Magnífico, en una de- 


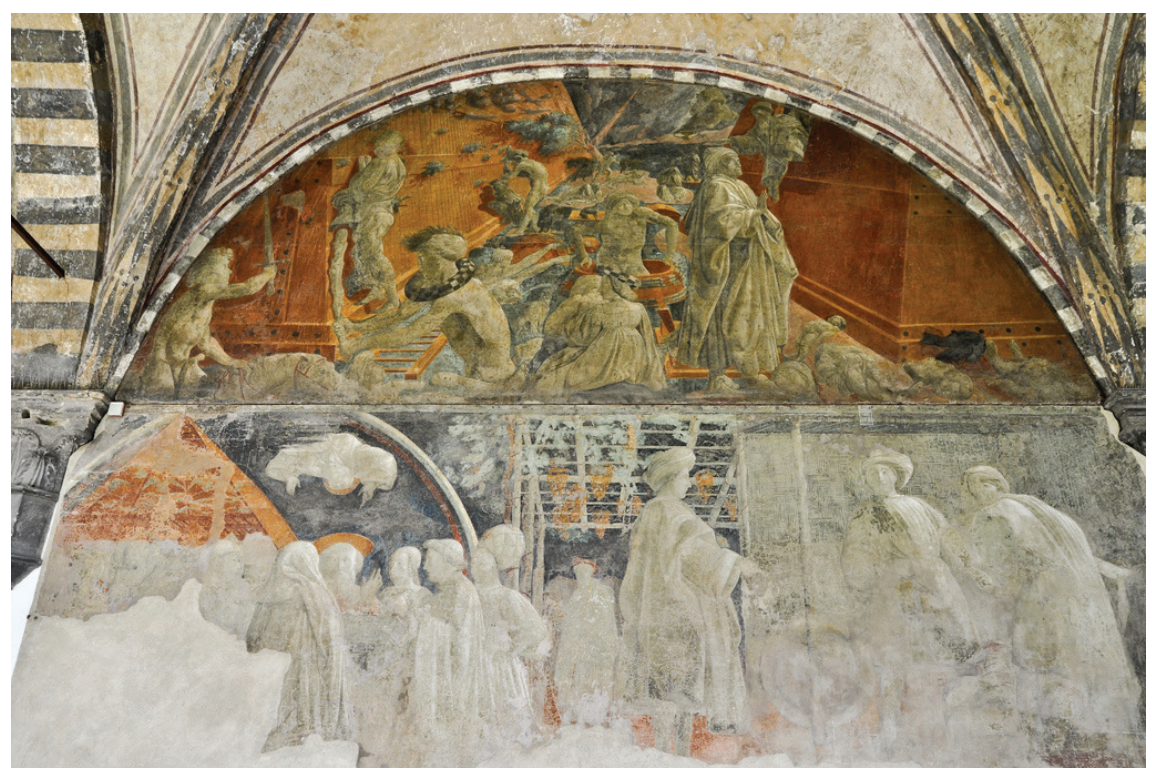

Fig. 12. Uccello, Historias de Noé, Chiostro Verde, Santa Maria Novella.

Personajes de estas Batallas cubren sus cabezas con el mazzocchio, característico copricapo, muy utilizado en Florencia durante el Quattrocento; para Uccello pasó a ser un objeto ideal, convenientemente geometrizado, para sus experimentaciones perspectívicas; tanto en diseños como en taraceas lígneas, llegó a conformarse como instrumento científico ${ }^{45}$.

\section{Búsquedas y hallazgos, 1436-1460}

Importante etapa para Uccello y sus investigaciones que, de algún modo, es factible y elocuente encuadrar, siempre con un punto de duda respecto a sus fechas de ideación y ejecución, mediante sus dos versiones del tema de San Jorge y la Princesa; o sea, el San Jorge de París (c. 1440) y el San Jorge de Londres (c. 1460) ${ }^{46}$.

El formato más horizontal de la tabla de París, permite al artista presentar en primer plano la escena propiamente dicha, según una visión prácticamente frontal, de

terminada sala del piso bajo del palacio Medici Riccardi, y aquí continuaban en 1498; desde 1435, con toda probabilidad, en la denominada "Casa Vieja de Via Larga" de Cosme el Viejo.

45 Es el caso de Estudio de Mazzocchio en perspectiva, c. 1470 (Uffizi); como taracea de madera, integraba el contenido de una de las alacenas ilusionísticas, en el Studiolo de Federico da Montefeltro en el palacio ducal de Urbino.

46 Vid. Borsi-Uccello, "I due San Giorgio. Il Santo, la Bella e la Bestia", pp. 44-45; Padoa-Uccello, cat. 21, pp. 120-121 (témpera sobre tabla, 52 X 90 cm., Musée Jacquemart André, París) y cat. 22, pp. 122-123 (témpera sobre tela, 57 X $73 \mathrm{~cm}$., National Gallery, Londres). 


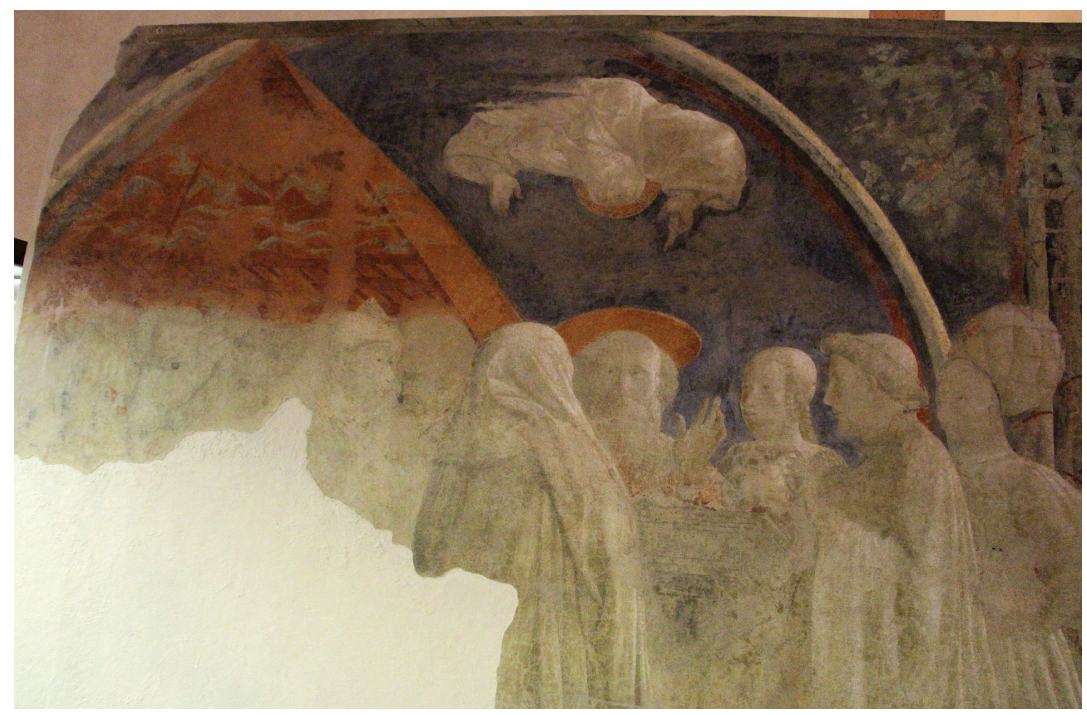

Fig. 13. Uccello, Sacrificio de Noé, det., Chiostro Verde.

raigambre escenográfica y de marcada tendencia abstractizante, que contrasta con un paisaje planteado a vista de pájaro, casi al modo de soluciones geometrizantes de Ambrogio Lorenzetti; escenificación congelada, como en las Batallas, ante una "pacífica" naturaleza.

En la obra londinense todo parece precipitarse hacia el espectador, al tiempo que presenta una notoria reducción de elementos accesorios y la búsqueda de una mayor profundidad. Ante una exangüe princesa a la izquierda, queda escenificada la lucha entre fiera y caballero, según la convergencia de dos ejes perspectívicos que avanzan desde los fondos laterales; insólito en este momento, profundizando en lo ensayado en el San Juan en Patmos de la predella di Quarata, plasma Uccello desde un fondo oscuro de tormenta, un torbellino de nubes que, entre efecto natural de ciclón y dimensión milagrosa, parece impulsar y proyectar hacia delante al santo caballero en el cumplimiento de su misión; verdaderamente una solución digna del mismísimo Leonardo.

De 1443 datan los cartones para tres vidrieras de la catedral de Florencia que, en los años siguientes, serán traducidos a vidrio y plomo; perdida una Anunciación, restan en el presbiterio catedralicio una muy restaurada Natividad y una Resurrección; en esta última orquesta Uccello magistralmente todas las posibilidades, en claves lumínico-expresivas, de un arte bien conocido por el artista. Curvando la figura de un Cristo erecto sobre una peana, consigue convertirle en un foco lumínico que irradia luz a todo el entorno circular, del cual destacan dos abatidos soldados que llevan el correspondiente mazzocchio.

Para la Catedral asimismo, c. 1443, diseña y realiza el Cuadrante de reloj (Fig. 11) con cabezas de profetas de su contrafachada; pintura que presenta una subdivisión mediante números romanos en veinticuatro horas, con una disposición de los 


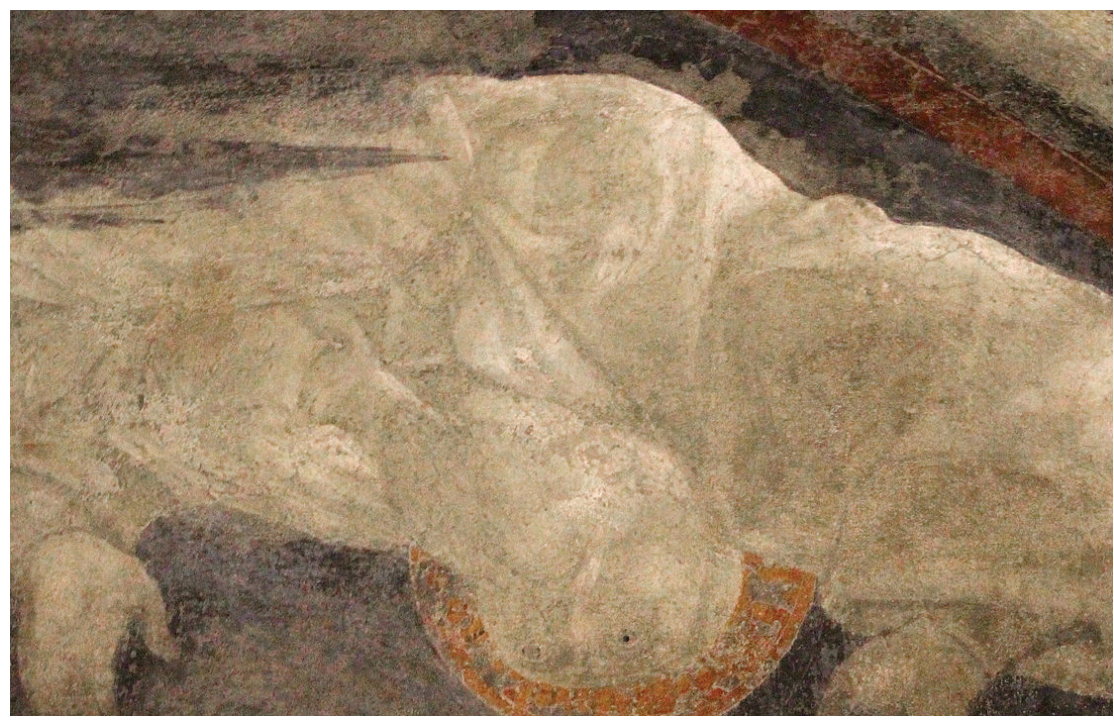

Fig. 14. Uccello, Sacrificio de Noé, det., Chiostro Verde.

mismos en sentido antihorario que reclama la posición de las horas sobre antiguos meridianos. Los profetas y sus fisionomías quieren "rimar" o hacer relación a los donatellianos, esculturas entonces en la fachada, están hoy en el Museo dell'Opera del Duomo, Florencia.

La data c. 1445, es quizá la más conveniente para la Virgen y el Niño, tabla conservada hoy en Dublín ${ }^{47}$, que supone un importante testimonio de la experimentación de Uccello. Las deformaciones ópticas que, extremando la cercanía a la imagen -un estudio previo, se entiende- se reflejan en un espejo convexo, son aplicadas por el artista al Niño y en parte a la Virgen; el grupo dispuesto en una hornacina de la cual queda muy destacada su venera, no sólo es de una patente originalidad, sino que adquiere un inusitado sentido laico con ribetes incluso domésticos.

Historias relativas a Noé, el Diluvio Universal y sus consecuencias, completan el ciclo de frescos del Claustro Verde de Santa Maria Novella, iniciado unos veinte años antes; ocupan a Uccello a su retorno de Padua, 1445, junto a los citados de San Miniato al Monte (Figs. 12-13-14). Los del claustro dominicano, cuyo estado de conservación consienten una muy aceptable lectura, deben fecharse c. 1447, por más que no exista documentación ${ }^{48}$. Embriaguez y Sacrificio de Noé, comparten un mismo registro de formato rectangular; en el Sacrificio a la izquierda, el pintor plasma mediante una calculada ambigüedad de imágenes, a Dios Padre en arriesgado escorzo que, en realidad es el reflejo de la del propio patriarca, de Noé, devuelto por los vapores

47 Témpera sobre tabla, 57 X 33 cm., National Gallery of Ireland, Dublín; vid. Padoa-Uccello, cat. 6, pp. 60-61, donde se propone la fecha c. 1435-1440; ¿fragmento de una pintura más amplia?

48 En cualquier caso, posteriores a las sesiones del Concilio de las Iglesias, 1439; frescos en grisalla, y "tierra roja y verde"; Affreschi distaccati, sitos en la crujía Este del claustro. 


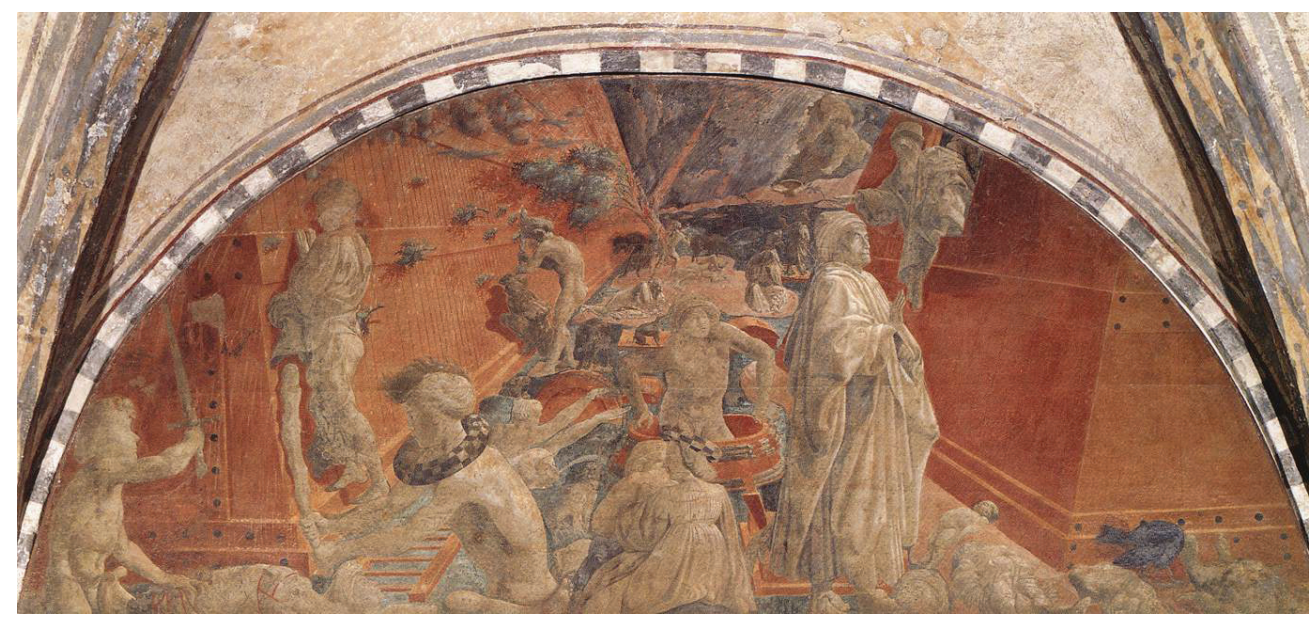

Fig. 15. Uccello, Diluvio Universal y retirada de las aguas, Chiostro Verde.

suspendidos en el aire que, tanto como fenómeno atmosférico como simbólico, queda evidenciado por la presencia del arco iris, que reafirma la reconciliación con Dios.

Sobrepuesto al anterior en un medio punto rebajado, diseñó y realizó Uccello, la que acaso fue y sigue siendo, su obra más celebrada y de constante interés para los estudiosos; se trata de la representación al unísono del Diluvio y la retirada de las aguas. Pintura absolutamente paradigmática, ponderada incluso por el propio Vasari como obra realizada con mucho trabajo y mucha diligencia, donde Uccello plasmó la tempesta, il furore de'venti ... il troncar degli alberi e la paura degli uomini, de tal modo y con tal fuerza che più non si può dire. (Figs. 15-16-17)

La obra con su duplicidad de momentos sugiere, en cambio, casi un mismo planteamiento perspectívico, desde luego no unitario y con puntos de fuga divergentes, pero tanto figuras como toda una diversidad de elementos quedan orquestados, según una sabia composición, en un espacio único de connotaciones urbanas y delimitado mediante sendas superficies del arca, que aparece duplicada según dos distintas vistas de angulaciones diversas, pero que logran crear un sugestivo escenario en el cual quedan ensambladas, en un unicum sin parangón en la pintura quattrocentesca, naturaleza subvertida y tragedia humana según una personalísima visión del relato bíblico ${ }^{49}$.

\section{Uccello, últimas aportaciones}

La creación de algunas obras correspondientes a los últimos años de la vida de Uccello, evidencian el vigor, la creatividad y madurez de su mente fértil durante, más o menos, la década 1460-1470.

49 Figuras paralizadas y ensimismadas, una de ellas con un mazzocchio al cuello, pero exentas de hieratismo; vid. Borsi-Uccello, pp. 32 y 34-35. 


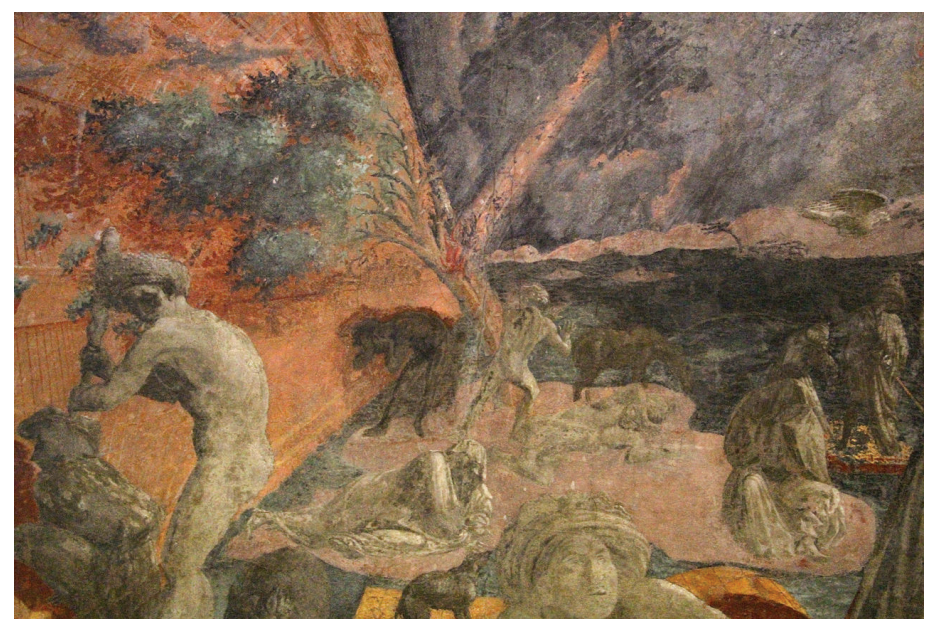

Fig. 16. Uccello, Diluvio, det., Chiostro Verde.

La denominada Tabla del Louvre, Ritratto di cinque uomini illustri, que, en mi opinión nada tiene que ver con Uccello, ha sido repetidamente asociada con éste recordando la atribución de Vasari (sólo en las Vite, 1568, ya que en las Vite, 1550, en un increíble lapsus, quedaba bajo paternidad de Masaccio). Obviamente según una inscripción muy posterior, uno de los bustos pintados corresponde a Uccello, lo cual ha conllevado la consideración de autorretrato y, dada su fisionomía y al margen del resto de efigies, de fecha tardía ${ }^{50}$, c. 1470 . Reciente y óptimamente rehabilitada, lo interesante de la tabla ante todo es, a mi entender, su "discurrir" de Giotto a Brunelleschi, pasando por Uccello y Donatello.

Por su parte la Crucifixión con santos ${ }^{51}$, asimismo fechable c. $1470 \mathrm{y}$, con referencias a la predella de Urbino, verdaderamente parece ser una obra de colaboración, como ha sido sugerido, de Uccello con sus hijos pintores Donato y Antonia; las connotaciones caricaturescas de los santos suponen un cierto "mordiente" propio del maestro, que se pierde en un forzado ritmo gesticulante y en la búsqueda de un fondo de paisaje más convencional.

Las Escenas de vida eremítica o Tebaida, con una "excesiva ordenación”, con todos los "episodios en su sitio" y el convencionalismo compositivo, hacen de esta pintura algo ajeno a la poética y a la sabiduría de Uccello, al tiempo que son fehacientes

50 Vid. Padoa-Uccello, cat. 25, p.129 (42 X 210 cm.); fuentes de momentos diversos, se argumenta aquí, pudieron servir para los cuatro maestros restantes, de izquierda a derecha Giotto, Uccello, Donatello, Antonio di Tuccio Manetti y Brunelleschi, o sea una secuencia eminentemente florentina y como hitos significativos de su devenir artístico. La obra, al parecer, perteneció a Giuliano da Sangallo y, como recuerdo-homenaje, tanto puede ser de fines del Quattrocento como de inicios del Cinquecento.

51 A la Virgen y San Juan Evangelista flanqueando a Cristo crucificado, usualmente Calvario, se suman San Juan Bautista (patrono de Florencia) y San Francisco, lo cual parece indicar que fue una obra para un cenobio franciscano de la ciudad del Arno o sus entornos (Padoa-Uccello, cat. 24, témpera sobre tabla, 46 X $67,5 \mathrm{~cm}$., Museo Thyssen, Madrid), parece posterior a la predela de Urbino. 


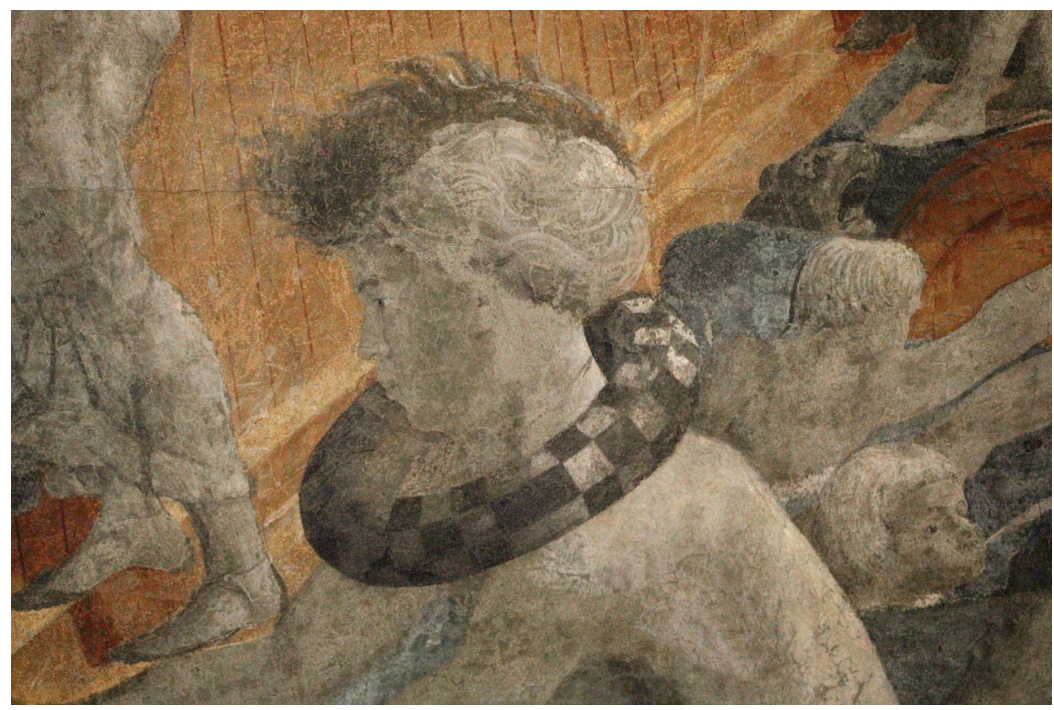

Fig. 17. Uccello, Diluvio, det. personaje con mazzocchio, Chiostro Verde.

las constantes citas al mismo; obra ajena, por tanto al maestro y no anterior a 1480 , como ha sido propuesto ${ }^{52}$; con el apoyo en diseños del padre, es muy probablemente obra realizada por alguno de sus hijos pintores, ya reseñados. La más más aceptable sería la autoría de Antonia, la figlia suora e pittrice de Paolo Uccello.

Pero sin duda alguna, las obras maestras correspondientes a este período que aquí se glosa, son la Predella de Urbino y la Caccia de Oxford, de las cuales dimanan todo el ingenio y maestría del Uccello maduro; la estancia del maestro en la corte de Federico da Montefeltro, ha quedado constatada durante el intervalo 1465-1468; en abril de 1469, el pintor ya había regresado a Florencia.

En la obra de Urbino, Uccello narra el Milagro de la hostia profanada ${ }^{53}$, de modo peculiar y siempre sorprendente, en seis episodios divididos por unos anchos balaustres rojizos, que son decisivos elementos actuantes, sobre el muy apaisado formato, como pernos que parecen rotar de viñeta a viñeta, sin interrumpir el relato pictórico desarrollado en una continuidad visual (Figs. 18-19-20-21); toda una secuencia de espacios represados, otros abiertos a paisajes de amplísima profundidad, y otros, en fin, con fragmentos arquitectónicos, y todos con pequeñas figuras, voluntariamente reducidas y esquematizadas, con sesgos caricaturescos sobre todo en los grupos y cortejos ceremoniales.

Su destino era el altar de la Compagnia del Corpus Domini di Urbino, institución de patrocinio ducal y, de manera específica, en relación con la duquesa Battista Sfor-

52 Vid. Padoa-Uccello, cat. 28, pp. 133-134; tela, 80 X 109 cm., Galleria dell'Accademia, Florencia.

53 Vid. Padoa-Uccello, cat. 19, pp. 111-117; témpera sobre tabla, 43 X 351 cm., Galleria Nazionale delle Marche, Urbino; se conserva también aquí la obra de Justo de Gante y, muy oportunamente, se exponen por separado en esta institución museística con sede en el propio Palacio Ducal de Urbino. 


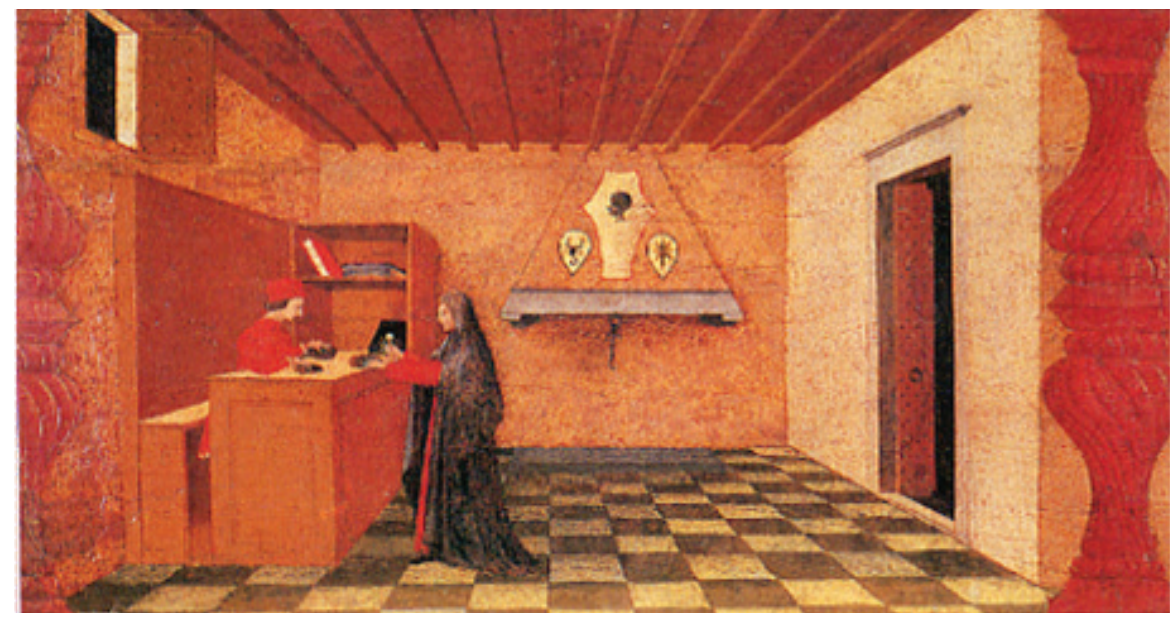

Fig. 18. Uccello, predella di Urbino, det.

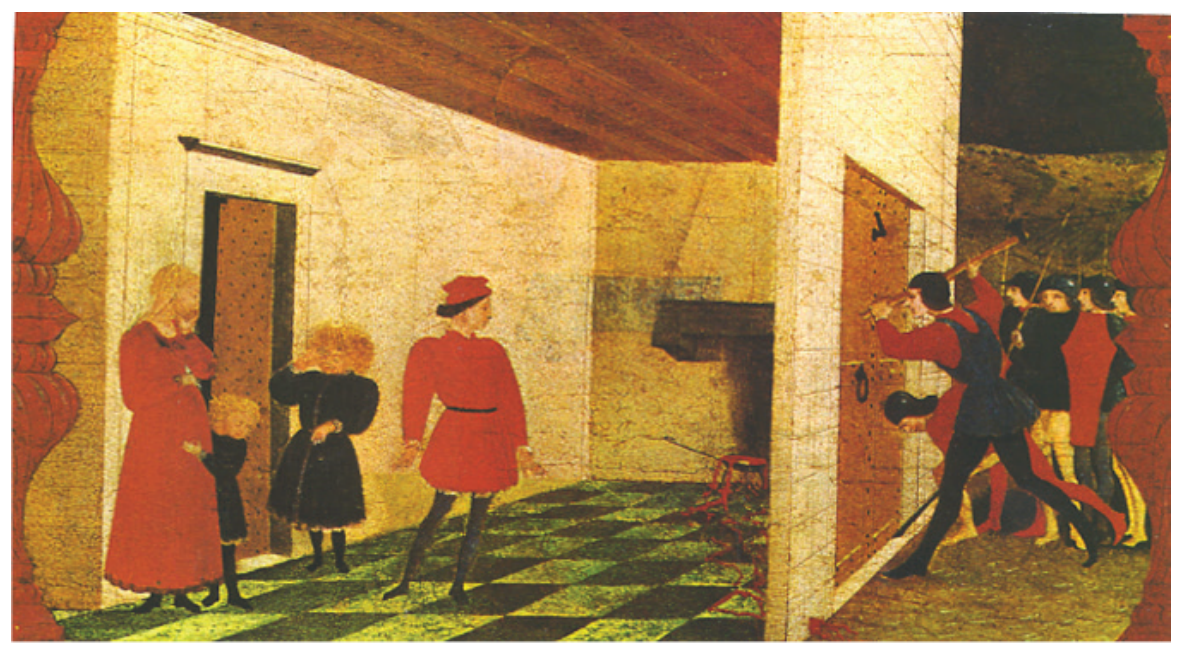

Fig. 19. Uccello, predella di Urbino, det.

za; estaba prevista como predella de la Comunión de los apóstoles que, habiendo ya Uccello abandonado la ciudad, pintara Justo de Gante.

Pintura absolutamente magistral a todos los niveles, contando además con un excelente estado de conservación, la Cacería Nocturna ${ }^{54}$, usualmente la Caccia de Oxford, es un más que digno remate para estas consideraciones sobre Paolo Uccello y su obra. (Fig. 22)

54 Vid. Padoa-Uccello, Caccia al cervo, cat. 23, pp. 124-127; témpera sobre tabla, 65 X 165 cm., Ashmolean Museum, Oxford. 


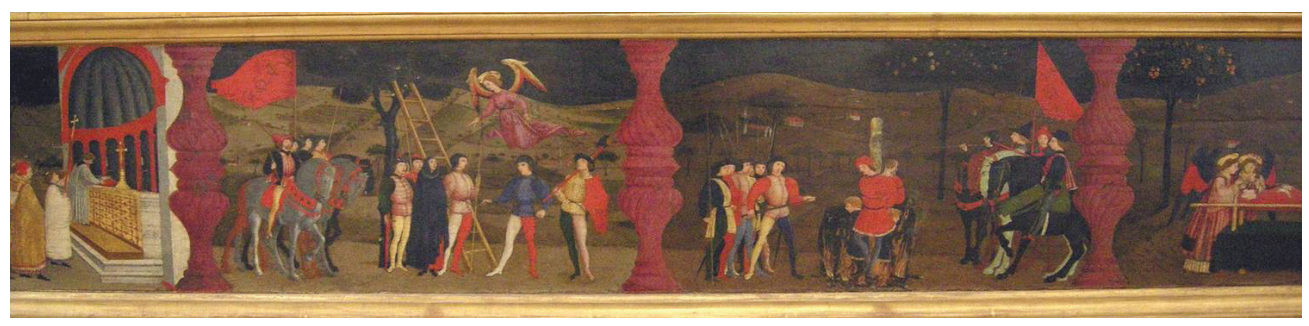

Fig. 20. Uccello, predella di Urbino, det.

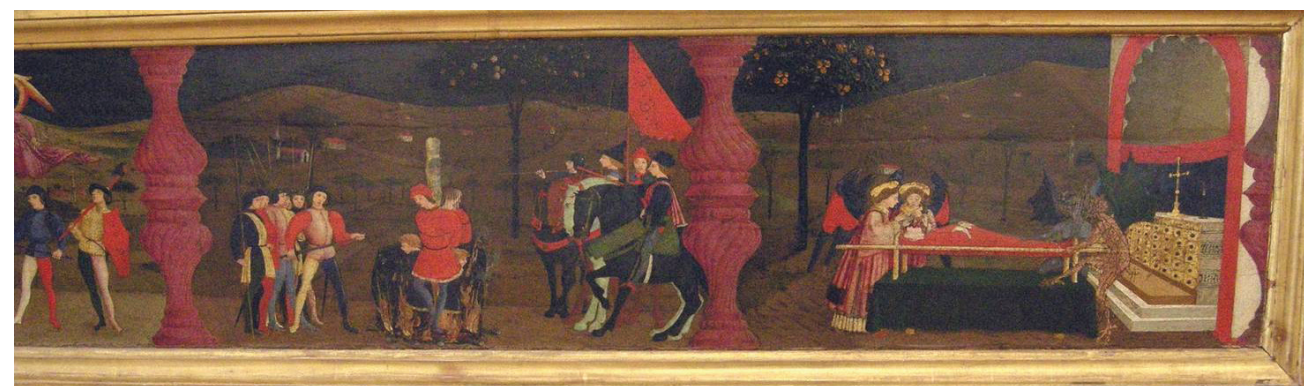

Fig. 21. Uccello, predella di Urbino, det.

Mediante una "vuelta de tuerca" más, el infatigable maestro nos propone la escenificación, nunca mejor dicho, según una visión unitaria, de un nocturno y una cacería en un bosque; se trata de profundizar en sus propias experimentaciones, para lograr un unicum, nunca mejor dicho también, para crear el contexto fascinante de una noche casi mágica; pintura que corresponde al intervalo 1467-1469.

Una inscripción en la parte posterior de la tabla de Oxford ("Una caccia nelli Boschi di Pisa di Benozzo Gozzoli”), más tardía y ajena a la obra, ha sido relacionada con una poesía contemporanea sobre una Caccia di Lorenzo il Magnifico, asociando así la pintura con un encargo de este Medici, dando por descontado que la autoría de un artista-artigiano como Benezzo sería imposible, llegándose a proponer incluso la data de c.1470, como pintura de Uccello obviamente.

Mucho más probable y verosímil es que fuera parte de una spalliera del palacio de Urbino, encargo de un culto comitente como Federico da Montefeltro, recordada en varios inventarios posteriores del Palacio Ducal, como caccia al cervo; spalliera, al parecer conformada por "i Mesi, basata sull'Astronomicum" del poeta y astrólogo latino Manilio.

La arboleda boscosa avanza hasta el primer término, como es apreciable en la parte superior de la tabla, y está construida con un extraordinario rigor perspectívico casi arquitectónico $\mathrm{y}$, en esta pintura, de manera innegablemente unitaria, como quedó reseñado, conformando el adecuado proscenio de toda la escena (Figs. 23-24); una refinadísima técnica pictórica fue utilizada por Uccello en esta obra, sin diseño subyacente y con muy pocos pentimenti. Los árboles, al contrario que las figuras, están 


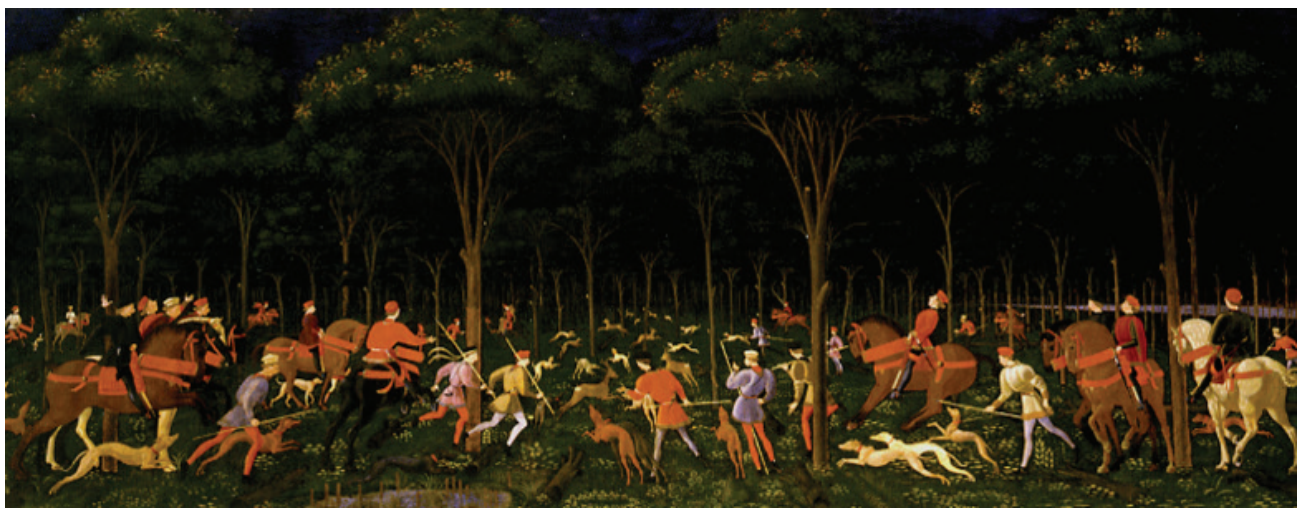

Fig. 22. Uccello, Caccia de Oxford.

pintados sobre una preparación negra y con toques de luz en las hojas obtenidos con sutiles láminas de oro ${ }^{55}$.

Poniendo en práctica sus profundos conocimientos de óptica, Uccello, en la penumbra verde oscura, logra que los colores brillen según las varias situaciones de luz -los rojos verdaderamente titilan ante nuestros ojos- pautando un ritmo intenso y sincopado, una visión de calibrados reflejos y fulgores que, tras captar al espectador, le "introduce" en este sugestivo ámbito haciéndole partícipe de la propia caza y "conducirle" en su trayectoria, esto es focalizando su mirada que, por otro lado, puede detenerse en deliciosos "accidentes" como el rectilíneo río, en la parte superior derecha, o en el remanso acuoso con plantas lacustres, de la zona inferior izquierda. Sólo Leonardo estará en condiciones de recibir este testigo.

\section{(Addenda: Alhazén, Bacon, Vitellone)}

Hacia 1021 es datado el Libro de la Óptica de Alhazén considerado el "padre" de esta disciplina dentro de la Física ${ }^{56}$, base fundamental para la perspectiva medieval.

Ibn al-Haydam -conocido en Occidente, donde tuvo un decisivo influjo, como Alazén- fue un auténtico ápice de la ciencia árabe que, precisamente entre los siglos XI y XIII, vivió una época de esplendor. Fue también importante astrónomo y matemático, siendo fundamentales, no obstante, sus aportaciones a la Óptica, como queda explicitado, considerando los rayos lumínicos como trazos rectos y plantear

55 Vid. Borsi-Uccello, pp. 46-47.

56 Como corolario a menudo se señala que Newton, en el campo de la óptica, descansa sobre los hombros de "un gigante" que vivió setecientos años antes que él; algo bastante cierto en buena medida, en función de los métodos rigurosamente experimentales y con todo tipo de comprobaciones -es decir, científicamente planteados y ratificados- sobre el ojo y la visión, los rayos lumínicos desde fuentes primarias y secundarios, reflexión y refracción de la luz y diseño y experimentaciones con lentes, espejos y en la denominada Cámara Oscura. Cuestiones todas claves para la visión y la perspectiva naturalis. 


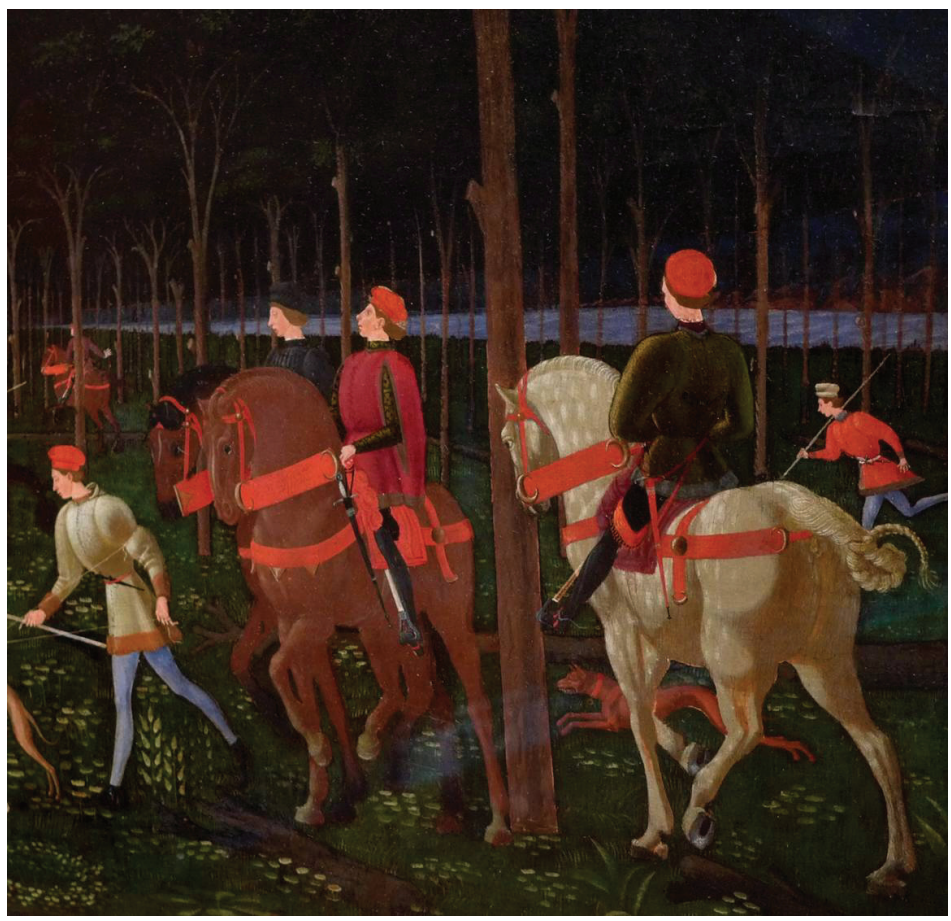

Fig. 23. Uccello, Cassia de Oxford, det.

los objetos visualizados como fuentes secundarias de luz; estos conjuntos de fuentes puntuales emiten rayos en todas direcciones.

El legado de Alhazén, que a su vez hacía lo propio y desarrollaba el saber grecoromano, es retomado por Roger Bacon, en el siglo XIII, cuyos estudios de óptica incluidos en su magna obra, actualizó significativas vertientes del tema, que tuvieron una notable difusión en la península italiana, sobre todo sus ideas sobre la luz como la primigenia de las entidades sensibles.

Con Witelo ${ }^{57}$ se alcanza un punto culminante del tema, asume e impulsa las aportaciones de Alhazén-Bacon, al tiempo que constituye una directa referencia para Uccello vía Ghiberti; en efecto, este sabio Thuringorum et Polonorum filius, estudió en la Universidad de Padua, hasta c. 1260, pasando luego a Viterbo donde entabla amistad con Guillermo de Moerbeke, traductor de Aristóteles. En esta localidad italiana concluye, su tratado de óptica Perspectiva, c. 1270-1278, que dedica precisamente a Moerbeke.

57 Con posterioridad su obra llegó a la imprenta: "WITELO, Jakub .. Peri Optikes ... De Natura, Ratione, \& Projectione Radiorum Visus, Luminum, Colorum Atque Formarum, Quam Vulgo Perspectivam Vocant, Libri X'. Nüremberg, Johann Petri, 1535. Asimismo, junto a la versión latina de la obra de Alhazén (De aspectibus o Perspectivae) la obra de Witelo fue impresa en Basilea en 1572 por Friedrich Risner, con el título Opticae Thesaurus. 


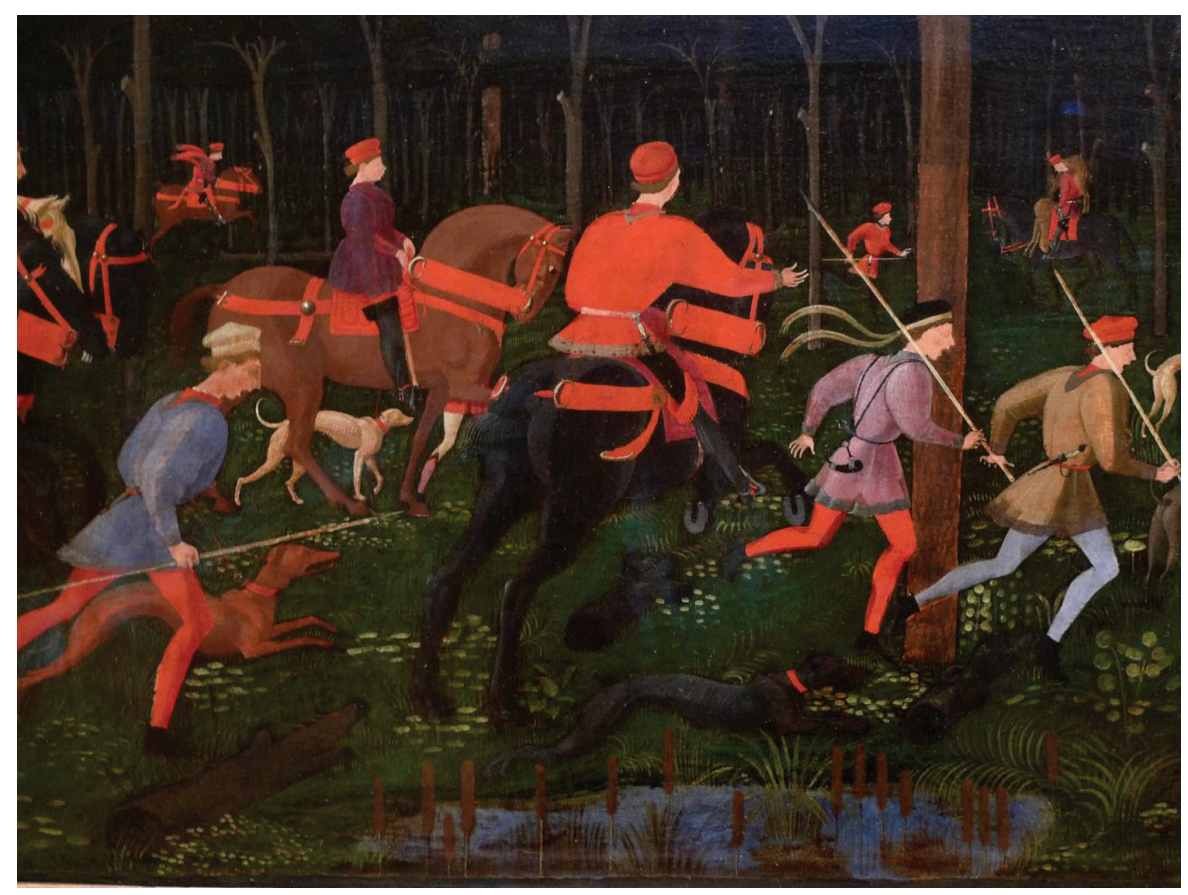

Fig. 24. Uccello, Caccia de Oxford, det.

La traducción al italiano del tratado de Witelo fue básico para el Commentario terzo ghibertiano que, a partir del primero, plasma aspectos y datos psicológicos cercanos a las actuales nociones de asociación de ideas y del subconsciente; sugestiones que debieron captar asimismo la atención de Paolo Uccello. 